\author{
UNIVERSIDADE DE SÃO PAULO \\ FACULDADE DE ECONOMIA, ADMINISTRAÇÃO E CONTABILIDADE \\ DEPARTAMENTO DE ECONOMIA \\ PROGRAMA DE PÓS-GRADUAÇÃO EM ECONOMIA
}

\title{
Benefit Sharing na Exploração de Recursos Hídricos no Brasil
}

Tiago Pontes Ferraz

Orientador: Prof. Dr. Fernando Antonio Slaibe Postali

São Paulo - Brasil

2016 
Prof. Dr. Marco Antonio Zago

Reitor da Universidade de São Paulo

Prof. Dr. Adalberto Américo Fischmann

Diretor da Faculdade de Economia, Administração e Contabilidade

Prof. Dr. Hélio Nogueira da Cruz

Chefe do Departamento de Economia

Prof. Dr. Márcio Issao Nakane

Coordenador do Programa de Pós-Graduação em Economia 


\title{
Benefit Sharing na Exploração de Recursos
}

\section{Hídricos no Brasil}

\author{
Dissertação apresentada ao Programa de \\ Pós-Graduação em Economia do Depar- \\ tamento de Economia da Faculdade de \\ Economia, Administração e Contabilidade \\ da Universidade de São Paulo como requisito \\ parcial para a obtenção do título de Mestre \\ em Ciências.
}

Orientador: Prof. Dr. Fernando Antonio Slaibe Postali

Versão Original

São Paulo - Brasil

2016 
FICHA CATALOGRÁFICA

Elaborada pela Seção de Processamento Técnico do SBD/FEA/USP

Ferraz, Tiago Pontes

Benefit sharing na exploração de recursos hídricos no Brasil / Tiago Pontes Ferraz. - São Paulo, 2016.

$76 \mathrm{p}$.

Dissertação (Mestrado) - Universidade de São Paulo, 2016.

Orientador: Fernando Antonio Slaibe Postali.

1. Royalties 2. Compensação 3. Usinas hidrelétricas I. Universidade de São Paulo. Faculdade de Economia, Administração e Contabilidade. II.Título.

$$
\text { CDD }-305.522
$$


Aos meus pais, Valter e Ana, por tudo o que fizeram por mim durante toda a vida. Esta conquista também é de vocês. 



\section{Agradecimentos}

À minha esposa Maristela, pelo apoio incondicional, pelo amor e dedicação ao longo destes anos e por ser a principal responsável por todas as minhas conquistas na vida.

Ao Professor Fernando Antonio Slaibe Postali, por sua imensa paciência e dedicação como orientador neste período. Considero-me uma pessoa de muita sorte por ter tido a oportunidade de trabalhar com ele nos últimos dois anos.

Às professoras Fabiana Fontes Rocha e Maria Dolores Montoya Diaz, por todas as críticas e sugestões durante o processo de qualificação, que foram essenciais na definição dos rumos deste trabalho.

A todo o corpo docente da Faculdade de Economia, Administração e Contabilidade da Universidade de São Paulo, que muito contribuíram para minha formação.

Ao apoio financeiro, por meio de bolsa, da Coordenação de Aperfeiçoamento de Pessoal de Nível Superior (CAPES).

A todos os meus colegas da pós-graduação, com os quais tive o privilégio de participar de discussões riquíssimas. 



\section{Resumo}

Grandes projetos de infraestrutura podem provocar impactos permanentes em seu entorno, afetando negativamente a qualidade de vida da população local. Para mitigar os impactos causados pela instalação de usinas hidrelétricas, a legislação brasileira prevê que os municípios sejam compensados por meio da Compensação Financeira pelo Uso de Recursos Hídricos (CFURH) e/ou pelo pagamento de royalties (ITAIPU). Este trabalho testa a hipótese de que estas compensações têm funcionado de fato como mecanismo de benefit sharing, examinando seus efeitos sobre alguns indicadores sociais e econômicos usando um método em dois estágios: primeiro estima-se o propensity score dos municípios beneficiados pelas compensações, usando dados georreferenciados de elevação do terreno e disponibilidade de água, extraídos da base de dados do projeto HydroSHEDS do WWF e uma série de outros controles. Em seguida, estima-se um modelo difference-in-differences, comparando as variáveis dependentes nos grupos de tratamento e controle, antes e depois de começarem a receber as compensações. Os resultados encontrados mostram que o impacto das compensações foi bastante limitado. O IDH-M e a mortalidade infantil apresentaram pequena melhora, mas a taxa de analfabetismo e a desigualdade de renda pioraram.

Palavras-chaves: benefit-sharing, CFURH, royalties, propensity score, differencein-differences, duplamente robusto. 



\section{Abstract}

Large infrastructure projects may cause permanent impacts on their environment, negatively affecting the living conditions of local people. To mitigate impacts caused by installation of hydroelectric plants, Brazilian law provides that municipalities are compensated by the Compensação Financeira pelo Uso de Recursos Hídricos (CFURH) and the payment of royalties (Itaipu). This work tests the hypothesis that such payments have actually worked as a benefit sharing mechanism, examining its effects on some social and economic indicators using a two stages method: first, the propensity score of municipalities benefiting from the compensation is estimated using GIS elevation and flow accumulation data from WWF's project HydroSHEDS. Then, it is estimated a difference-in-differences model, comparing the dependent variables in the control and treatment groups before and after the compensations. The results show a limited effect of the compensations. Human Development Index (HDI) and infant mortality showed a little improvement, but illiteracy rate and income inequality worsened.

Key-words: benefit-sharing, CFURH, royalties, propensity score, diff-in-diff, doubly robust. 



\section{Sumário}

1 Introdução. . . . . . . . . . . . . . . . . 19

2 Revisão da Literatura . . . . . . . . . . . . . . . . . . . . . . 23

3 Dados e Amostra . . . . . . . . . . . . . . . . . . . . 27

4 Estratégia Empírica . . . . . . . . . . . . . . . . . 31

4.1 Modelo Econométrico . . . . . . . . . . . . . . . . . . . . . . 31

4.2 Estratégia de Identificação . . . . . . . . . . . . . . . . . . . . 33

5 Resultados. . . . . . . . . . . . . . . . . . . . . 37

5.1 Resultados Gerais . . . . . . . . . . . . . . . . . . . . . 39

5.2 Efeitos Heterogêneos . . . . . . . . . . . . . . . . . . . . 44

6 Robustez dos Resultados . . . . . . . . . . . . . . . . . . . . 49

7 Possíveis Canais dos Efeitos . . . . . . . . . . . . . . . 55

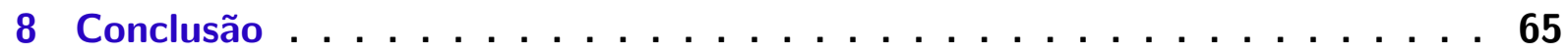

Referências . . . . . . . . . . . . . . . . 67

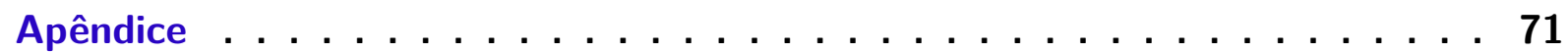





\section{Lista de ilustrações}

Figura 1 - Evolução dos Valores de CFURH e Royalties de Itaipu Distribuídos aos Municípios - 2000-2010 ( $\mathrm{R} \$$ de 2010) . . . . . . . 20

Figura 2 - Distribuição Espacial dos Municípios Beneficiários de CFURH e/ou Royalties . . . . . . . . . . . . . . . . . . . 29

Figura 3 - Distribuição do propensity score, por grupo . . . . . . . . . . 37

Figura 4 - Evolução dos indicadores socioeconômicos em municípios tratados e não tratados: 1970-2010 . . . . . . . . . . . . . 50 50 



\section{Lista de tabelas}

Tabela 1 - Estimação do $1^{\text {a }}$ estágio - Propensity Score . . . . . . . . . . . . 38

Tabela 2 - Balanceamento das covariadas. . . . . . . . . . . . . 40

Tabela 3 - Estimativas do efeito médio do tratamento sobre os tratados (ATT) $2^{\circ}$ Estágio . . . . . . . . . . . . . . . . . . . 42

Tabela 4 - Estimativas do efeito médio do tratamento sobre os tratados (ATT) $2^{\circ}$ Estágio . . . . . . . . . . . . . . . . . . 43

Tabela 5 - Efeito médio do tratamento sobre os tratados (ATT) ajustado à correlação serial . . . . . . . . . . . . . . . . . . . . . . 45

Tabela 6 - Efeitos heterogêneos . . . . . . . . . . . . . . . 46

Tabela 7 - Efeitos heterogêneos: municípios tratados antes de 2000 . . . . . . . . 48

Tabela 8 - Efeito médio do tratamento sobre os tratados (ATT), incluindo tendências específicas de estado e região geográfica . . . . . . . . . . . . . 52

Tabela 9 - Efeito médio do tratamento sobre os tratados (ATT), incluindo tendências específicas de estado e região geográfica, excluindo municípios sede de barragens e/ou casa de máquinas . . . . . . . . . . . . . . . 53

Tabela 10 - Impacto das compensações sobre a provisão de bens públicos: Vacinação,

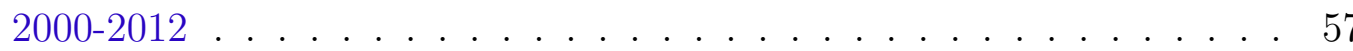

Tabela 11 -Impacto das compensações sobre a provisão de bens públicos: Matrículas na rede municipal, 2000-2012 . . . . . . . . . . . . . . . 58

Tabela 12 -Impacto das compensações sobre gastos públicos, 2000-2012 . . . 60

Tabela 13 -Impacto das compensações sobre as despesas com pessoal, 2000-2012 62

Tabela 14 -Impacto das compensações sobre os investimentos, 2000-2012 . . . 63

Tabela 15 -Estatísticas Descritivas: Variáveis dependentes . . . . . . . . . . . . 72

Tabela 16 -Estatisticas descritivas: Covariadas . . . . . . . . . . . . . 73

Tabela 17 -Balanceamento das covariadas, por decil . . . . . . . . . . . . . 74 
Tabela 18 -Balanceamento das covariadas, excluindo municípios sede de barragens e/ou casa de máquinas . . . . . . . . . . . . . . . . . 75

Tabela 19 -Balanceamento das covariadas, por decil, excluindo municípios sede de barragens e/ou casa de máquinas . . . . . . . . . . . . . . 76 


\section{Introdução}

A implantação e operação de uma usina hidrelétrica provocam grandes impactos no município que a recebe, tanto positivos (como a geração de empregos e renda) quanto negativos (reassentamento de famílias ribeirinhas, impactos ambientais decorrentes do alagamento de grandes áreas, etc.). Em muitos casos, os impactos negativos podem ser de caráter permanente: a formação do reservatório pode alterar o equilíbrio dinâmico da fauna aquática e provocar mudanças estruturais na vegetação, erosão do solo, assoreamento dos rios, etc. Numa outra dimensão, pode se configurar um enorme desafio ao desenvolvimento econômico e social das localidades onde a usina é instalada. Cernea (2008) aponta que em muitos casos o reassentamento de famílias provocado pela implantação de grandes projetos de infraestrutura tem causado seu empobrecimento, em grande parte porque as políticas de indenização têm sido insuficientes para a manutenção de suas condições de vida.

Buscando mitigar estes efeitos a Lei federal n ${ }^{\circ}$ 7.990/1989 instituiu para os Estados, Distrito Federal e Municípios a Compensação Financeira Pelo Uso de Recursos Hídricos (CFURH), um benefício monetário pela exploração do potencial hidráulico para geração de energia elétrica, a ser pago por usinas hidrelétricas com capacidade nominal superior a $30 \mathrm{MW}^{1}$.

O principal objetivo das compensações é ressarcir os municípios pela perda da área alagada e pelo uso da água (ANEEL, 2014). Mas, mais do que isto, elas podem ser entendidas como a repartição de uma renda econômica da geração de energia hidrelétrica. Segundo Rothman (2000), usinas hidrelétricas podem gerar rendas econômicas porque são limitadas as localidades em que podem ser implantadas e porque alguns empreendimentos conseguem gerar energia a um custo menor do que outras tecnologias ou ainda porque fatores sazonais podem limitar a disponibilidade de água nas barragens. A existência destas rendas é a principal justificativa para adoção de mecanismos de benefit sharing com

1 Até 1996 a lei estabelecia a isenção da contribuição para usinas com capacidade nominal até $10 \mathrm{MW}$. A lei 9.427/96, que criou a ANEEL, estendeu o benefício para os empreendimentos com capacidade até 30 MW. Também estão isentos os autoprodutores cuja produção se restrinja ao seu próprio consumo. 
os municípios afetados.

Nos últimos anos houve um incremento considerável do volume de recursos transferidos aos municípios a título de compensações. A Figura 1 mostra a evolução destas transferências entre 2000 e 2010. Houve um salto de cerca de R $\$ 570$ milhões para um pouco mais de $\mathrm{R} \$ 850$ milhões, aqui incluídos CFURH e royalties de Itaipu.

Figura 1: Evolução dos Valores de CFURH e Royalties de Itaipu Distribuídos aos Municípios - 2000-2010 ( $\mathrm{R} \$$ de 2010)

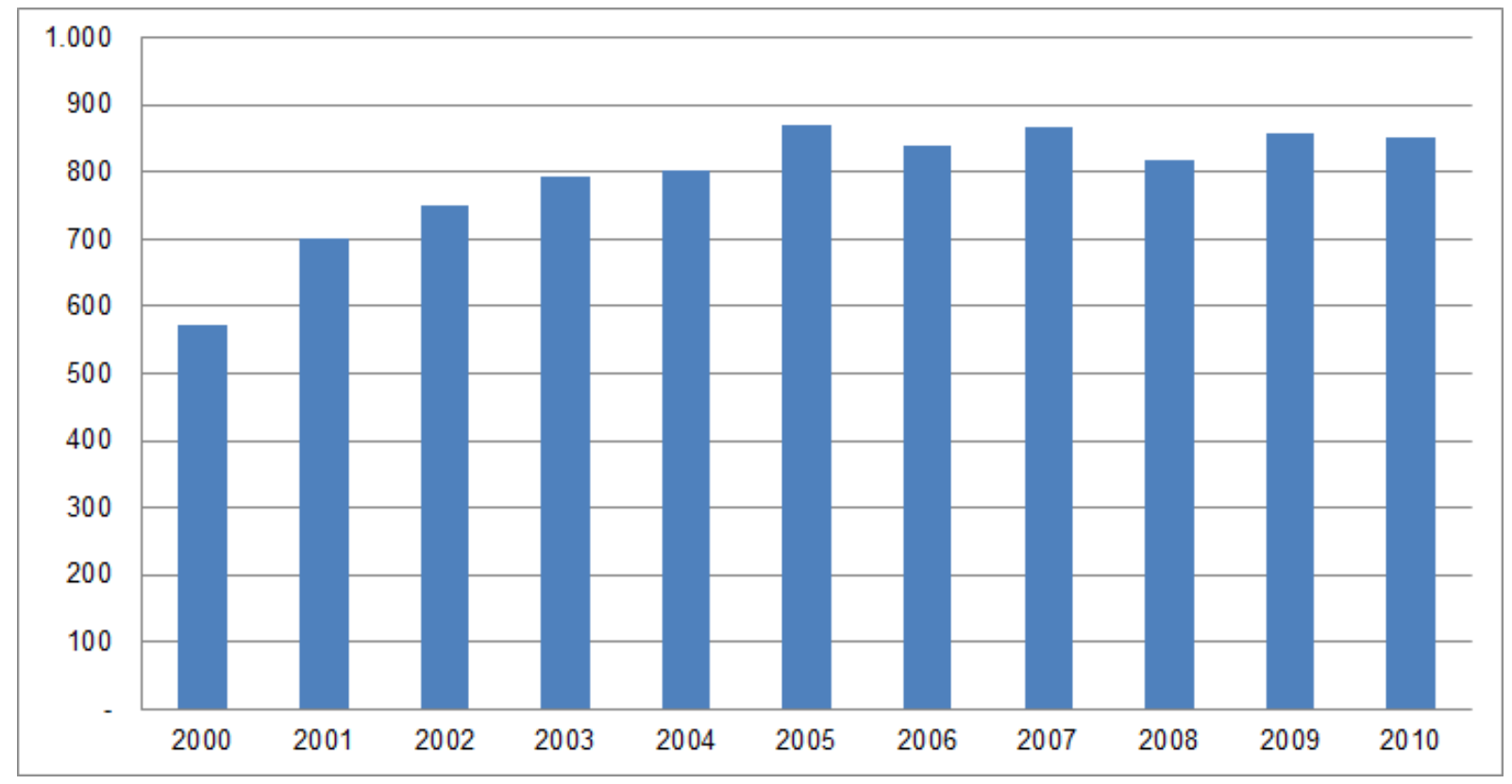

Fonte: Elaboração própria com base em dados da ANEEL (2014)

Num cenário de baixa produção hidrelétrica, que entre outros fatores poderia ser causada por restrições na disponibilidade hídrica dos reservatórios, a potencial queda desta receita para os municípios pode afetar de maneira decisiva sua capacidade de implementar políticas públicas, colocando em risco a qualidade de vida de sua população. De acordo com a ANEEL, 163 municípios (quase um quarto dos beneficiários) receberam compensações em volume maior do que sua arrecadação tributária própria em 2010, o que dá uma ideia da importância desta fonte de recursos. Assim, torna-se bastante relevante entender se estas transferências de fato têm tido impacto significativo sobre a qualidade de vida dos indivíduos nas localidades mais afetadas pelas usinas.

A Constituição Federal de 1988 diz em seu Art. 20 que os potenciais de energia 
hidráulica são bens da União e assegura aos Municípios, Distrito Federal e Estados participação na compensação financeira pela exploração destes recursos. A Lei federal $\mathrm{n}^{\mathrm{o}}$ 7.990/1989 determina que as usinas recolham mensalmente à Secretaria do Tesouro Nacional (STN) 6,75\% do valor da energia produzida, montante obtido pela multiplicação da quantidade de energia produzida (medida em MW/hora) pela Tarifa Atualizada de Referência (TAR) calculada anualmente pela ANEEL. Esta mesma lei e suas alterações posteriores vedam o uso destes recursos para (i) pagamento de dívidas (exceto àquelas contraídas junto à União e suas entidades) e (ii) quadro permanente de pessoal. ${ }^{2}$

No caso da usina de Itaipu, por se tratar de um empreendimento binacional, a compensação financeira se dá na forma de royalties distribuídos igualmente a ambos os países, conforme determina o artigo XV do Tratado de Itaipu. O cálculo dos royalties é feito com base na fórmula: Energia Gerada (GWh) x US\$ 650 x Taxa de Câmbio x 4 (ANEEL, 2014).

A Lei federal $n^{\circ}$ 9.984/2000 estabelece que do valor total arrecadado pela CFURH, 0,75\% deve ser destinado ao Ministério do Meio Ambiente para implementação da Política Nacional de Recursos Hídricos e do Sistema Nacional de Gerenciamento de Recursos Hídricos. Do valor restante, $45 \%$ deve ser distribuído aos municípios e Distrito Federal ${ }^{3}$. A mesma fórmula de distribuição se aplica aos royalties de Itaipu. Cabe à ANEEL informar à STN os valores a serem distribuídos para os municípios, de acordo com (i) a proporção de área alagada em cada município e (ii) o ganho de energia proporcionado a outras usinas localizadas a jusante no mesmo rio.

Esta dissertação tem como objetivo testar a hipótese de que estas compensações têm funcionado como um mecanismo de benefit sharing, examinando seu impacto sobre uma série de indicadores socioeconômicos. Para isto, será estimado um modelo em dois estágios (duplamente robusto): no primeiro estágio estima-se um propensity score dos municípios beneficiados pelas compensações. No segundo estágio, usando o propensity

2 A Lei $\mathrm{n}^{\circ}$ 12.858/2013 excluiu desta vedação as despesas com remuneração de professores da rede pública.

3 Do total distribuído, $45 \%$ vai para os estados, 3\% para o Ministério do Meio Ambiente (MMA), $3 \%$ para o Ministério de Minas e Energia (MME) e 4\% para o Fundo Nacional de Desenvolvimento Científico e Tecnológico (FNDCT). 
score como ponderador das variáveis independentes, estima-se um modelo difference-indifferences, comparando as médias das variáveis dependentes nos municípios beneficiados e não beneficiados, antes e depois de começarem a receber as compensações. A escolha deste método visa lidar com o problema de viés de variável omitida, que é a principal ameaça à identificação causal dos efeitos das compensações sobre os indicadores socioeconômicos.

Para além desta introdução, este trabalho conta com outros 7 capítulos. No capítulo 2, é feita uma revisão da literatura relevante. No capítulo 3, é apresentada a base de dados e amostra utilizada. No capítulo 4, é discutida a estratégia empírica para estimar o impacto das compensações. No capítulo 5, são mostrados os resultados gerais da estimação e a heterogeneidade explorada. Nos capítulos 6 e 7 são discutidos os exercícios realizados para verificar a robustez das estimativas e os possíveis canais pelos quais as compensações podem afetar os indicadores socioeconômicos, respectivamente. Finalmente, no capítulo 8 apresenta-se a conclusão. 


\section{Revisão da Literatura}

O termo benefit sharing é usado neste trabalho no sentido definido por Wang (2012): esforços sistemáticos por parte dos proponentes de um projeto para beneficiar de maneira sustentável as comunidades locais por ele afetadas. Diversos trabalhos que tratam da exploração de recursos naturais apontam a existência de rendas econômicas como a principal justificativa para a implantação de mecanismos de benefit sharing com as localidades diretamente afetadas pelos empreendimentos. Cernea (2008) sugere que estas rendas sejam utilizadas para complementar as indenizações de modo que as localidades possam investir no bem estar da população reassentada. Ele ainda cita o caso da CFURH no Brasil como exemplo de benefit sharing que poderia ser incorporado nas diretrizes das políticas de reassentamento. McDonald (2006) aponta que a China foi o primeiro país a incluir explicitamente em sua política de reassentamento a noção de oportunidades para o desenvolvimento humano. O autor analisa o projeto da Barragem das Três Gargantas, a maior usina hidrelétrica do mundo, que provocou o reassentamento de mais de um milhão de moradores. Através da aplicação de questionários e entrevistas com reassentados ele conclui que apesar de não ter havido melhoras significativas nas condições de vida destas pessoas, tampouco houve empobrecimento.

Entretanto, a evidência empírica não é muito clara a respeito dos impactos das rendas de recursos naturais na promoção do bem estar. Por exemplo, Postali (2009) avalia o efeito dos royalties do petróleo sobre a evolução do PIB municipal, antes e depois da aprovação da Lei do Petróleo (Lei Federal no 9.478/1997). O resultado encontrado é que municípios que recebem royalties apresentam um crescimento econômico menor do que os não beneficiados, sugerindo uma espécie de maldição dos recursos naturais. Resultado similar foi encontrado por Caselli e Michaels (2013), que estudam o efeito de um choque positivo nas receitas municipais, causado pelos royalties do petróleo. Os autores mostram que os royalties provocam um aumento nos gastos públicos em diversas áreas como habitação e infraestrutura urbana, educação, saúde e transportes. No entanto, este 
aumento de gastos não se traduz em melhores indicadores sociais em todas estas dimensões.

Por outro lado, Postali e Nishijima (2013) investigam o impacto dos royalties de petróleo numa série de indicadores socioeconômicos captados nos censos de 1991 a 2010. Os resultados encontrados indicam que estas rendas de fato contribuíram para a melhora na infraestrutura dos domicílios (acesso a água e eletricidade) e redução na taxa de analfabetismo nos municípios beneficiários.

No caso específico das rendas provenientes de recursos hídricos, Monasterio e Sousa (2014) estimam os efeitos da CFURH sobre renda per capita, redução do esforço fiscal e elevação do IDH-M, entre os anos 2000 e 2010, sem encontrar resultados significativos. Segundo os autores, a CFURH tem efeito nulo (ou até mesmo negativo) sobre a taxa de crescimento da renda per capita e do IDH-M.

Uma possível explicação para estes resultados conflitantes pode ser buscada na literatura que trata da chamada "Maldição dos Recursos Naturais". Esta literatura se desenvolveu apoiando-se, a princípio, na hipótese de "Doença Holandesa": um choque positivo na renda de recursos naturais pode provocar uma redução na renda agregada da economia, via apreciação da taxa de câmbio (SACHS; WARNER, 1995). Ao longo do tempo, novas explicações foram incorporadas, destacando-se o papel das instituições no mecanismo que relaciona recursos naturais ao desenvolvimento econômico. Mehlum, Moene e Torvik (2006) afirmam que a abundância de recursos pode criar incentivos políticos perversos que seriam mitigados apenas em países com boas instituições. O principal resultado encontrado é que a qualidade das instituições determina se os empreendedores vão se especializar na produção ou na extração de rendas. Robinson, Torvik e Verdier (2006) constroem um modelo em que o político incumbente tem de decidir quanto extrair do estoque de recursos naturais e como redistribuir estas rendas entre seu próprio consumo, transferências aos indivíduos e emprego no setor público, de modo que possa obter apoio político e ser reeleito. O principal resultado do modelo é que um boom nas rendas de recursos naturais incentiva uma redistribuição com vistas a obter apoio político nas eleições, mas em países com boas instituições estas práticas clientelistas podem ser limitadas. 
Uma explicação alternativa, embora ainda relacionada às contribuições acima mencionadas, pode ser buscada na literatura de economia política que trata da maneira como os governos locais gastam os recursos disponíveis no orçamento e como os eleitores percebem estes gastos. Se os eleitores se preocupam mais com os recursos que saem diretamente de seus bolsos, os políticos em exercício podem ter menor incentivo a gastar bem os recursos que são transferidos por outras esferas de governo. Litschig e Morrison (2013) estudam o impacto do FPM nos gastos governamentais e na provisão de bens públicos (educação, transporte, habitação e infraestrutura urbana) nos municípios brasileiros, no período 1980-1991. Eles mostram que o aumento nas transferências via FPM elevam os gastos per capita, aumenta a escolaridade e a taxa de alfabetização e diminui a pobreza. Além disto, eles identificam que o aumento nos gastos públicos eleva a probabilidade de reeleição do partido incumbente. Brollo et al. (2013) argumentam que um choque positivo nas receitas exacerba os problemas de agência e deteriora o pool de candidatos concorrendo pelos cargos políticos. O político incumbente enfrenta um trade-off entre extrair rendas ou melhorar a provisão de bens públicos para agradar aos eleitores e aumentar suas chances de reeleição. Eles testam as predições do modelo numa amostra de municípios brasileiros, analisando o impacto do Fundo de Participação dos Municípios (FPM) nos casos de corrupção detectados em auditorias realizadas pela Controladoria Geral da União (CGU) e na probabilidade de reeleição dos prefeitos. Os resultados encontrados mostram que um aumento nas transferências aos municípios aumenta a detecção de casos de corrupção e também aumenta a probabilidade de reeleição do incumbente, ao mesmo tempo em que reduz a proporção de competidores com nível superior de escolaridade.

O objetivo deste trabalho é investigar se existem evidências de que as compensações (CFURH e royalties de Itaipu) tenham afetado positivamente um conjunto de indicadores sociais. O ponto de partida é o artigo de Monasterio e Sousa (2014), segundo o qual "Os valores da CFURH são distribuídos de acordo com critérios técnicos, exógenos às ações das prefeituras". De fato, uma vez que uma usina hidrelétrica é instalada em determinada localidade, parece razoável tratar o recebimento das compensações como exógeno. No entanto, o mecanismo de seleção dos municípios que serão compensados pode não ser. 
Existem vários fatores, alguns observáveis outros não, que determinam a probabilidade de um dado município receber uma usina hidrelétrica. Se alguns destes fatores estiverem correlacionados com os indicadores socioeconômicos, isto pode confundir a identificação do efeito como causal. Por exemplo, a existência de um rio com suficiente volume d'água é uma das principais condições para que se possa instalar uma usina. Ao mesmo tempo, isto também poderia afetar a aptidão agrícola do solo que pode ser correlacionada com o crescimento econômico; ou ainda, as características de um determinado rio podem determinar presença de certos tipos de insetos, o que pode estar correlacionado com questões de saúde pública, etc. Esta dissertação espera contribuir com a literatura empírica que trata dos impactos das rendas de recursos hídricos sobre bem estar. A estratégia econométrica adotada procura lidar com o problema de viés de variável omitida, que é a principal ameaça à identificação do efeito causal. 


\section{Dados e Amostra}

Neste capítulo são apresentadas a amostra e as principais fontes de dados utilizadas no trabalho.

Para avaliar o impacto da política de compensações, são usados os seguintes indicadores da qualidade de vida da população: IDH-M, expectativa de anos de estudo, taxa de analfabetismo (população de 11-14 anos e de 15 anos ou mais), mortalidade infantil (mortes por 1000 nascidos vivos, até 1 ano de idade), renda per capita (renda média mensal dos indivíduos residentes, em $\mathrm{R} \$$ de 2010$)$, índice de Gini, percentual da população vivendo em situação de pobreza extrema e percentual da população em domicílios com acesso à água encanada, coleta de lixo e energia elétrica. Todas estas informações foram coletadas na base de dados Atlas do Desenvolvimento Humano do PNUD - Programa das Nações Unidas para o Desenvolvimento. Por se tratar de dados censitários, estão disponíveis apenas para os anos de 1991, 2000 e 2010. Em 2010, o Brasil possuía 5.565 municípios, mas não foi possível obter dados de todas as variáveis para todos os períodos. As Tabelas 15 e 16 apresentam as estatísticas descritivas e fornecem um resumo da amostra utilizada.

A principal preocupação em relação à identificação está nos fatores que determinam a localização das usinas, em especial as características geográficas que determinam o potencial de geração de energia. A mais importante destas características é a vazão da água que irá passar pelas turbinas para gerar energia, a qual depende, basicamente, da quantidade de água disponível e das variações na elevação do terreno por onde passa o curso d'água. Para poder controlar por estas características, foram construídas as variáveis de topografia (elevação do terreno e disponibilidade de água), sob inspiração do trabalho de Lipscomb, Mobarak e Barham (2013), usando a base de dados HydroSHEDS, um projeto do WWF (World Wide Fund for Nature) que usa imagens de satélite para criar uma base de dados georreferenciados com uma ampla gama de informações sobre bacias hidrográficas. As imagens têm uma resolução de 30 arco-segundos (cada pixel tem cerca 
de $1 \mathrm{~km}^{2}$ na linha do equador). Usando uma ferramenta GIS (Geographic Information System) para abrir o shapefile dos municípios brasileiros e fazer a sobreposição com as imagens de satélite, foram calculados o desvio padrão da elevação do terreno (em metros) e a média de disponibilidade de água (o número de pixels convergindo) em cada pixel. Em seguida, foi usado o shapefile da hidrografia brasileira para criar um buffer com raio de $1 \mathrm{~km}$ em torno de cada rio, gerando 210.809 polígonos distribuídos sobre o território brasileiro que foram sobrepostos ao shapefile da malha municipal. Assim, foi possível extrair as médias de disponibilidade de água e da variação na elevação do terreno dentro de cada polígono, em cada município, o que dá uma medida das características topográficas no entorno dos rios. A razão para se criar esta medida, ao invés de simplesmente usar uma média das características topográficas dentro do município, é evitar possíveis vieses que poderiam surgir se as características topográficas estivessem correlacionadas com as variáveis de resultado por algum outro canal além das compensações. Por exemplo, se numa determinada região dentro de um município houver pouca variação na elevação do terreno, pode ser mais fácil (menor custo) construir neste local. Neste caso, pode ser que a estimação estivesse capturando o efeito da atividade econômica da ocupação do terreno, não o das compensações. Ao restringir a análise para as características no entorno dos rios, se reduz a possibilidade de que outros fatores estejam confundindo a identificação.

Outra variável importante para determinar a localização de uma usina é o acesso a linhas de transmissão. Novamente, foi utilizado o shapefile dos municípios brasileiros que, ao ser sobreposto ao shapefile das linhas de transmissão (disponível no website da ANEEL), permitiu determinar todos os municípios pelos quais passa alguma linha.

Os dados de transferências governamentais foram obtidos da base de dados Finanças Públicas do Brasil (FINBRA), da Secretaria do Tesouro Nacional (STN), enquanto as informações de características da população também foram extraídas do Atlas do Desenvolvimento Humano.

Os municípios beneficiados pela CFURH e/ou royalties estão distribuídos em 22 estados, mas com alguma concentração nas regiões Sul e Sudeste, como se pode ver na 
Figura 2. O tamanho do círculo indica o volume de compensações per capita.

Figura 2: Distribuição Espacial dos Municípios Beneficiários de CFURH e/ou Royalties

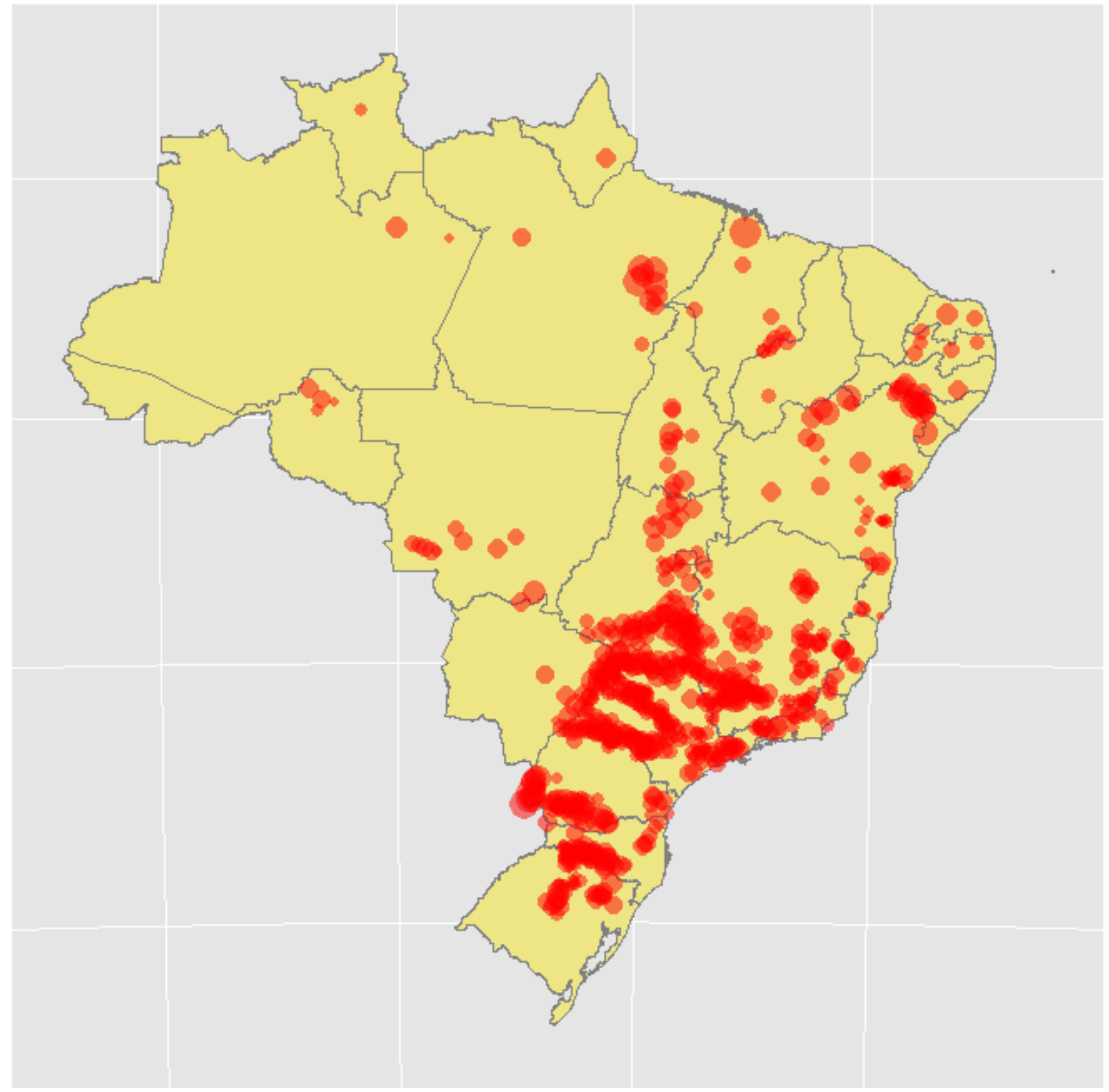

Fonte: Elaboração própria com base em dados da ANEEL (2014) 



\section{Estratégia Empírica}

\subsection{Modelo Econométrico}

Neste capítulo é apresentada a estratégia empírica adotada e discutidas as principais hipóteses de identificação.

O principal interesse deste trabalho é estimar o impacto das compensações sobre os indicadores socioeconômicos dos municípios beneficiários (tratados). Para isto, seria preciso saber como teria sido seu desempenho se não tivessem recebido o tratamento, algo que não se pode observar. No entanto, é possível construir um grupo de controle que reúna características semelhantes ao grupo tratado em todas as dimensões observadas, de modo que a única diferença entre os dois grupos seja a existência do tratamento.

Para tanto, utiliza-se um método em dois estágios, similar ao que já foi feito por Biondi et al. (2012) e por Gadenne (2013). No primeiro estágio, usando um conjunto X de variáveis observáveis, é estimada a probabilidade (propensity score) de um determinado município receber o tratamento, $p(X)$. No segundo estágio, usando o propensity score como um ponderador de cada observação, estima-se um modelo difference-in-differences (DID) comparando os indicadores socioeconômicos nos grupos de tratamento e controle, antes e depois do tratamento.

O fundamento por trás desta estratégia é que ao ponderar cada observação pelo propensity score, se atribui maior peso aos municípios do grupo de controle que são mais parecidos com os do grupo de tratamento em todas as dimensões observadas, tornando os dois grupos efetivamente comparáveis.

Para que a identificação faça sentido, duas hipóteses fundamentais devem ser respeitadas:

i. Ignorabilidade do tratamento: $\left[Y_{1}, Y_{0} \Perp T \mid X\right]$, ou seja, dadas as características observadas os resultados potenciais independem do status de tratamento; 
ii. Suporte comum: $0<p(T=1 \mid X)<1, \forall X$, o que significa que para todo valor de $X$, uma determinada observação tem uma probabilidade não nula de pertencer ao grupo de tratamento $(T=1)$ ou ao grupo de controle $(T=0)$.

Rosenbaum e Rubin (1983) mostram que sob estas duas hipóteses, vale a chamada ignorabilidade forte:

$$
\left[Y_{1}, Y_{0} \Perp T \mid p(X)\right]
$$

Esta hipótese é essencial porque simplifica bastante o problema ao reduzir um vetor de covariadas a uma única dimensão - o propensity score -, tornando possível comparar os municípios nos dois grupos.

Conforme sugerido por Dehejia e Wahba (2002), no primeiro estágio foi estimado um modelo de resposta binária que assume uma distribuição logística (LOGIT), tal que:

$$
\hat{p}(X)=\hat{p}(T=1 \mid X)=f\left(\beta_{0}+\beta_{1} X_{1}+\ldots+\beta_{k} X_{k}\right)
$$

Onde $X$ é um vetor de $k$ variáveis observadas e $\beta_{0}, \ldots, \beta_{k}$ são os coeficientes estimados. Em seguida, a probabilidade estimada é usada para ponderar as observações de $X$, definido por Imbens e Wooldridge (2009) como:

$$
w_{i}= \begin{cases}\frac{\hat{p}\left(X_{i}\right)}{p} \frac{1-p}{1-\hat{p}\left(X_{i}\right)} \frac{1-T_{i}}{1-p} & , \text { se } T_{i}=0 \\ \frac{T_{i}}{p} & , \text { se } T_{i}=1\end{cases}
$$

Sendo $p=\sum_{n=1}^{n_{1}} \hat{p}(X) \mid T=1$ e $n_{1}$ o número de unidades no grupo de tratamento.

A regressão de $Y_{i}$ em $X_{i}$ ponderado por $w_{i}$ é o estimador que se busca neste trabalho: o efeito médio do tratamento sobre os tratados $(\text { ATT })^{1}$

$\overline{1}$ No caso do efeito médio do tratamento (ATE) o peso seria dado por:

$$
w_{i}= \begin{cases}\frac{1}{1-\hat{p}(X)}, & \text { se } T_{i}=0 \\ \frac{1}{\hat{p}(X)} & , \text { se } T_{i}=1\end{cases}
$$


No segundo estágio, o modelo estimado é:

$$
y_{i t}=\delta D_{i t}+\beta \tilde{X}_{i t}+\lambda_{t}+\mu_{i}+\varepsilon_{i t}
$$

Onde $y_{i t}$ é a variável dependente no município $i$ no ano $t, D_{i t}$ é uma variável dummy que assume o valor 1 se o município $i$ no ano $t$ pertence ao grupo de tratamento e 0 caso contrário, $\tilde{X}$ é o vetor de covariadas ponderadas pelo propensity score que variam entre municípios e no tempo, $\lambda_{t}$ é o efeito comum a todos os municípios no ano $t$ e $\mu_{i}$ é um efeito fixo de município. O termo de erro, $\varepsilon_{i t}$ captura os efeitos não observáveis que variam no tempo e entre municípios, e por hipótese são distribuídos independentemente dos efeitos fixos $\mu_{i}$ e $\lambda_{t}$. Entretanto, é possível que os erros $\varepsilon_{i t}$ estejam serialmente correlacionados entre municípios ou no tempo. Para lidar com este possível problema foram calculados os erros-padrão clusterizados por estado-ano.

\subsection{Estratégia de Identificação}

Nesta seção são discutidas as principais ameaças à estratégia de identificação adotada, que explora a variação no status de tratamento entre municípios ao longo do tempo. O argumento principal está baseado na ideia de que, controlados os fatores que determinam a localização da usina hidrelétrica, as compensações recebidas pelos municípios podem ser consideradas exógenas. Esta hipótese parece bastante razoável levando-se em conta que os valores distribuídos aos municípios dependem basicamente de dois fatores:

(i) Do volume de energia produzida, que é uma decisão da usina. Um possível argumento contrário seria de que a usina poderia se preocupar com a demanda local na hora de decidir onde se instalar. Embora esta possa ter sido uma questão relevante no passado é pouco provável que atualmente ainda exerça alguma influência sobre a decisão das usinas. Desde meados da década de 70 o sistema elétrico brasileiro é operado de forma coordenada no Sistema Interligado Nacional (SIN) pelas empresas 
geradoras e transmissoras de energia, através do Operador Nacional do Sistema (ONS) e regulado pela ANEEL. Esta operação centralizada garante que a energia gerada numa determinada localidade possa ser transferida para qualquer outra atendida pela rede de transmissão. Graças a esta interligação, a energia produzida num determinado município não vai, necessariamente, atender a demanda desta localidade, o que afasta preocupações de causalidade reversa (se a decisão de produção da usina fosse influenciada pelos indicadores econômicos do município). Atualmente, menos de $2 \%$ da demanda de energia do país é atendida fora deste sistema ${ }^{2}$.

(ii) Da tarifa atualizada de referência (TAR) que é definida anualmente pela ANEEL. Segundo o Decreto n ${ }^{\circ} 3.739 / 2001$ a TAR é calculada com base nos preços de venda ao sistema de distribuição de energia, excluídos os encargos setoriais, tributos, empréstimos compulsórios e custos de transmissão. Ou seja, trata-se de uma regra exógena estabelecida por um marco legal bem definido.

Assim, a maior preocupação em relação à identificação deve estar no mecanismo de seleção dos municípios tratados. Existem dois problemas centrais que devem ser considerados. O primeiro é a questão de causalidade reversa: a decisão de onde instalar uma usina pode estar sendo determinada por fatores específicos da localidade, correlacionados com as variáveis de resultado. Por exemplo, se o governo escolhesse um município mais pobre para receber uma usina pensando em estimular a economia local. O segundo problema é que podem haver fatores não observados afetando os grupos de tratamento e controle de modo distinto. Entretanto, Imbens e Wooldridge (2009) mostram que o uso do propensity score como um ponderador da regressão atenua o viés de variável omitida, levando a uma robustez adicional do estimador. De acordo com Bang e Robins (2005), se ao menos um dos modelos estiver corretamente especificado, o estimador será consistente (duplamente robusto).

As variáveis incluídas no vetor $X$ são as seguintes:

$\overline{2}$ Composta, basicamente, de pequenos sistemas isolados na região amazônica 
- Topografia (elevação do terreno e disponibilidade de água - em log): são os principais determinantes da seleção do município para o tratamento. Localidades com maior disponibilidade de água e maior variação na elevação do terreno devem ter maior probabilidade de receber uma usina;

- Linhas de transmissão (dummy): indica se existe ou não uma linha de transmissão passando pelo município. Localidades com acesso a linhas de transmissão têm maior probabilidade de receber uma usina;

- Transferências Governamentais (\% da receita orçamentária): indica o grau de fragilidade fiscal do município. A hipótese implícita é de que municípios mais dependentes de outras esferas têm menor poder discricionário sobre seus gastos e, portanto, podem ter maior dificuldade na implantação de suas políticas. Alternativamente, as transferências de outras esferas poderiam suavizar choques adversos na atividade econômica local;

- PIB per capita (em $\mathrm{R} \$$ ): controla para a riqueza do município. Hipótese de que municípios mais ricos deveriam ter melhores indicadores;

- População (em log): controla para o "tamanho" do município. Hipótese de que municípios mais populosos requerem maior infraestrutura. Por outro lado, uma população maior possibilita ganhos de escala nas políticas públicas adotadas;

- Área $\left(\mathrm{em} \mathrm{km}^{2}\right)$ : outro controle para tamanho do município. Hipótese de que municípios maiores também requerem mais infraestrutura, mas podem ter maior potencial econômico;

- Razão de dependência (razão entre o número de menores de 14 anos e maiores de 65 anos sobre a população com idade entre 15 e 64 anos): Hipótese de que municípios com maior razão de dependência devem apresentar piores indicadores, uma vez que estes municípios precisariam aumentar seus gastos com saúde e educação; 
- População Urbana (\% da população total): Controla pelo grau de urbanização do município. Hipótese de que municípios mais urbanizados tendem a ter melhor infraestrutura e melhores indicadores socioeconômicos;

- Dummies de região (CO, NO, NE, S, SE): captura efeitos fixos de região geográfica. 


\section{Resultados}

Neste capítulo são analisados os resultados da estimação do primeiro e segundo estágios. A primeira seção apresenta os impactos gerais das compensações sobre os municípios tratados. Na segunda seção exploram-se os efeitos heterogêneos de duas maneiras distintas: (i) restringindo o grupo de municípios tratados àqueles em que o volume de compensações per capita ultrapassa determinados níveis; (ii) restringindo o grupo de tratados aos municípios que recebem compensações desde 1992 (primeiro ano em que estas foram efetivamente pagas).

O primeiro estágio é a estimação do LOGIT para obtenção do propensity score. Como se pode observar na Figura 3 há uma grande massa de municípios do grupo de controle concentrada em torno de zero, sugerindo que a simples estimação de um painel de efeitos fixos poderia estar enviesada.

Figura 3: Distribuição do propensity score, por grupo

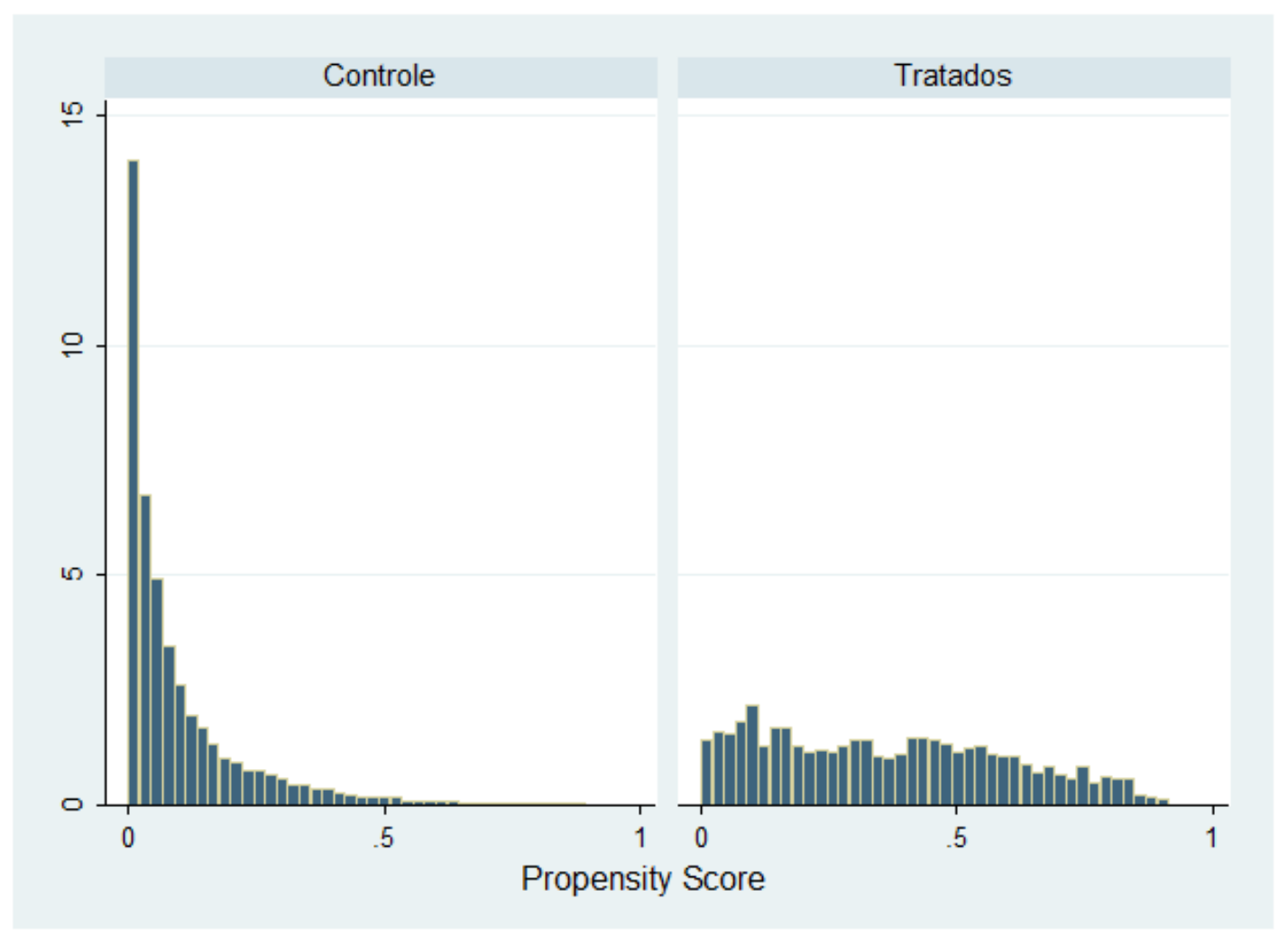

A Tabela 1 apresenta os resultados do primeiro estágio. Incluindo todas as covaria- 
das apresentadas na seção 2 , o pseudo $\mathrm{R}^{2}$ foi de 0,296 . A maioria delas foi significativa a $1 \%$ para explicar a probabilidade de um município receber compensações, com exceção da variável PIB per capita que é significativa apenas a $5 \%$.

Tabela 1: Estimação do $1^{\mathrm{a}}$ estágio - Propensity Score

\begin{tabular}{lclc}
\hline \hline & & & \\
Elevação do Terreno & $0.402^{* * *}$ & Área & $0.240^{* * *}$ \\
& $(0.044)$ & & $(0.033)$ \\
Disponibilidade de Água & $0.696^{* * *}$ & População Urbana & $0.008^{* * *}$ \\
& $(0.019)$ & & $(0.002)$ \\
Acesso a Linhas de Transmissão & $0.609^{* * *}$ & Dummy Região Sul & $0.555^{* * *}$ \\
& $(0.059)$ & & $(0.125)$ \\
Transferências Governamentais & $-0.012^{* * *}$ & Dummy Região Sudeste & $1.424^{* * *}$ \\
& $(0.002)$ & & $(0.110)$ \\
População & $-0.198^{* * *}$ & Dummy Região Norte & $-0.885^{* * *}$ \\
& $(0.039)$ & & $(0.223)$ \\
PIB per Capita & $0.008^{* *}$ & Dummy Região Nordeste & $-0.392^{* * *}$ \\
& $(0.004)$ & & $(0.146)$ \\
Razão de Dependência & $-0.045^{* * *}$ & Ano $=2000$ & $-0.439^{* * *}$ \\
& $(0.004)$ & & $(0.082)$ \\
Constante & $-6.478^{* * *}$ & Ano $=2010$ & $-0.827^{* * *}$ \\
& $(0.541)$ & & $(0.108)$ \\
& & & \\
\hline No Observações & 14.676 & & \\
Pseudo R ${ }^{2}$ & 0,296 & & \\
\hline \hline
\end{tabular}

A variável dependente é uma dummy que assume o valor 1 se o município pertence ao grupo de tratamento e 0 caso contrário. Erros-padrão robustos em parênteses. ${ }^{* * *}$ significante a $1 \%,{ }^{* *}$ significante a $5 \%,{ }^{*}$ significante a $10 \%$.

O objetivo do primeiro estágio é criar um suporte comum para as observações, como função do vetor de observáveis, tornando assim os dois grupos mais comparáveis. Para a criação deste suporte comum, foi seguido o procedimento adotado por Galiani, Gertler e Schargrodsky (2005):

a) No limite inferior foram excluídas as observações com propensity score inferior ao do $1^{\circ}$ percentil no grupo de tratamento;

b) No limite superior foram excluídas as observações com propensity score superior ao $99^{\circ}$ percentil do grupo de controle. 
Após a criação do suporte comum, é preciso verificar se os grupos de tratamento e controle são de fato comparáveis entre si, ou seja, se as covariadas do modelo estão balanceadas, a fim de evitar um possível viés de seleção. A Tabela 2 mostra que o balanceamento parece ter sido bem sucedido. Na primeira coluna, apresentam-se as diferenças de médias entre municípios tratados e não tratados, sem nenhum tipo de controle. Na segunda coluna, as diferenças apenas para os municípios pertencentes ao suporte comum. Finalmente, na terceira coluna são apresentadas as diferenças para os municípios pertencentes ao suporte comum, dado o propensity score. Uma vez que se adota este controle, apenas a variável Elevação do Terreno apresenta diferença estatisticamente significante a 10\%, mas esta diferença não chega a representar sequer 1\% da média desta variável.

Para garantir que os grupos de fato foram bem balanceados, foram testadas as diferenças de média em cada decil da distribuição de cada uma das variáveis. Estes resultados estão reportados na tabela 17 no Apêndice. Apesar de quase todas as variáveis apresentarem alguma diferença estatisticamente significante em algum decil de sua distribuição, estas são de pequena magnitude. Em nenhum destes casos a diferença chega a $10 \%$ da média da respectiva variável, o que sugere que os grupos de tratamento e controle apresentam boa comparabilidade.

\subsection{Resultados Gerais}

O objetivo deste trabalho é estimar o efeito médio do tratamento sobre os tratados (ATT). A estimação do segundo estágio, ou seja, da equação (4.4) é apresentada detalhadamente nas Tabelas 3 e 4. Os resultados encontrados mostram que as compensações têm um impacto positivo ${ }^{1}$, porém modesto sobre IDH-M e Mortalidade Infantil (equivalentes a aproximadamente 2,5\% das respectivas médias do grupo de tratamento em 1991); um pouco mais acentuado, mas negativo em Analfabetismo 11-14 Anos e um impacto pequeno

1 O sinal negativo em Mortalidade Infantil significa que os municípios tratados tiveram uma redução mais acentuada neste indicador do que os municípios não tratados, daí porque considera-se o impacto positivo 
Tabela 2: Balanceamento das covariadas

\begin{tabular}{|c|c|c|c|}
\hline & Sem Correção & Suporte Comum & $\begin{array}{l}\text { Suporte Comum } \\
\& \\
\text { Propensity Score }\end{array}$ \\
\hline Elevação Terreno & $\begin{array}{c}0.146^{* * *} \\
(0.018)\end{array}$ & $\begin{array}{c}0.049 * * \\
(0.020)\end{array}$ & $\begin{array}{c}0.040^{*} \\
(0.021)\end{array}$ \\
\hline Disponibilidade de Água & $\begin{array}{c}1.727^{* * *} \\
(0.039)\end{array}$ & $\begin{array}{c}0.905^{* * *} \\
(0.047)\end{array}$ & $\begin{array}{c}0.016 \\
(0.044)\end{array}$ \\
\hline Acesso a Linhas Trasmissão & $\begin{array}{c}0.226^{* * *} \\
(0.011)\end{array}$ & $\begin{array}{c}0.118^{* * *} \\
(0.014)\end{array}$ & $\begin{array}{c}0.002 \\
(0.014)\end{array}$ \\
\hline Transferências Governamentais & $\begin{array}{c}-3.878^{* * *} \\
(0.349)\end{array}$ & $\begin{array}{c}-1.379 * * * \\
(0.396)\end{array}$ & $\begin{array}{c}0.229 \\
(0.421)\end{array}$ \\
\hline PIB per Capita & $\begin{array}{c}2.304^{* * *} \\
(0.172)\end{array}$ & $\begin{array}{c}0.975^{* * *} \\
(0.177)\end{array}$ & $\begin{array}{c}0.300 \\
(0.189)\end{array}$ \\
\hline População & $\begin{array}{c}0.131^{* * *} \\
(0.026)\end{array}$ & $\begin{array}{c}0.140 * * * \\
(0.032)\end{array}$ & $\begin{array}{c}0.029 \\
(0.034)\end{array}$ \\
\hline Área & $\begin{array}{c}0.175^{* * *} \\
(0.030)\end{array}$ & $\begin{array}{c}0.074^{* *} \\
(0.036)\end{array}$ & $\begin{array}{c}0.014 \\
(0.038)\end{array}$ \\
\hline Razão de Dependência & $\begin{array}{c}-7.666^{* * *} \\
(0.371)\end{array}$ & $\begin{array}{c}-1.309^{* * *} \\
(0.350)\end{array}$ & $\begin{array}{c}0.366 \\
(0.371)\end{array}$ \\
\hline População Urbana & $\begin{array}{c}0.110^{* * *} \\
(0.005)\end{array}$ & $\begin{array}{c}0.047^{* * *} * \\
(0.006)\end{array}$ & $\begin{array}{c}-0.004 \\
(0.006)\end{array}$ \\
\hline
\end{tabular}

Notas: A primeira coluna apresenta as diferenças de médias entre os grupos de tratamento e controle sem nenhuma correção. A segunda coluna apresenta as diferenças apenas das variáveis pertencentes ao suporte comum. A terceira coluna apresenta as diferenças das variáveis ponderadas pelo propensity score e pertencentes ao suporte comum. Erros-padrão em parênteses. ${ }^{* * *}$ significante a $1 \%, * *$ significante a $5 \%,{ }^{*}$ significante a $10 \%$. 
e negativo ${ }^{2}$ sobre Índice de Gini (equivalente a cerca de $10 \%$ e $2 \%$ das respectivas médias do grupo de tratamento em 1991). Para os demais indicadores, não foram encontrados efeitos estatisticamente significantes.

2 Da mesma forma, um resultado positivo nestes indicadores sugere que a evolução nos municípios tratados foi menor do que nos municípios não tratados, daí o impacto negativo. 
Tabela 3: Estimativas do efeito médio do tratamento sobre os tratados (ATT) - $2^{\circ}$ Estágio

\begin{tabular}{|c|c|c|c|c|c|c|}
\hline & IDH-M & Anos Estudo & Renda per Capita & Água & Lixo & Eletricidade \\
\hline ATT & $\begin{array}{c}0.011^{* * *} \\
(0.003)\end{array}$ & $\begin{array}{l}-0.099 \\
(0.082)\end{array}$ & $\begin{array}{c}5.703 \\
(9.927)\end{array}$ & $\begin{array}{c}1.631 \\
(1.183)\end{array}$ & $\begin{array}{c}0.576 \\
(1.196)\end{array}$ & $\begin{array}{c}0.482 \\
(0.718)\end{array}$ \\
\hline Transf. Govern. & $\begin{array}{c}-0.121^{*} \\
(0.065)\end{array}$ & $\begin{array}{l}3.437^{*} \\
(2.026)\end{array}$ & $\begin{array}{c}-499.994^{* * *} \\
(178.469)\end{array}$ & $\begin{array}{c}50.189^{* *} \\
(25.173)\end{array}$ & $\begin{array}{c}80.564^{* *} \\
(33.506)\end{array}$ & $\begin{array}{l}24.802 \\
(17.675)\end{array}$ \\
\hline Razão Dep. & $\begin{array}{c}-1.659^{* * * *} \\
(0.138)\end{array}$ & $\begin{array}{c}-54.066^{* * * *} \\
(5.328)\end{array}$ & $\begin{array}{c}3,904.415^{* * *} \\
(428.705)\end{array}$ & $\begin{array}{c}-975.786^{* * * *} \\
(76.007)\end{array}$ & $\begin{array}{c}-857.415^{* * * *} \\
(99.683)\end{array}$ & $\begin{array}{c}-680.036^{* * *} \\
(68.200)\end{array}$ \\
\hline PIB per Capita & $\begin{array}{c}0.184 \\
(0.112)\end{array}$ & $\begin{array}{l}-0.112 \\
(2.738)\end{array}$ & & $\begin{array}{c}22.118 \\
(38.430)\end{array}$ & $\begin{array}{c}8.774 \\
(71.317)\end{array}$ & $\begin{array}{c}9.253 \\
(27.325)\end{array}$ \\
\hline População & $\begin{array}{c}-18.078^{* * * *} \\
(5.391)\end{array}$ & $\begin{array}{l}-216.427 \\
(153.809)\end{array}$ & $\begin{array}{c}-5,750.366 \\
(21,939.261)\end{array}$ & $\begin{array}{c}-6,666.319^{* * *} \\
(2,296.933)\end{array}$ & $\begin{array}{c}-10,518.721^{* * *} \\
(2,888.453)\end{array}$ & $\begin{array}{c}-8,573.372^{* * *} \\
(1,906.714)\end{array}$ \\
\hline Área & $\begin{array}{l}-1.905 \\
(4.164)\end{array}$ & $\begin{array}{c}263.513^{* *} \\
(119.301)\end{array}$ & $\begin{array}{c}-21,182.358 \\
(13,269.100)\end{array}$ & $\begin{array}{c}-5,312.863^{* * *} \\
(1,571.139)\end{array}$ & $\begin{array}{l}-3,601.908 \\
(2,309.758)\end{array}$ & $\begin{array}{c}-3,537.328^{* *} \\
(1,630.101)\end{array}$ \\
\hline Pop. Urbana & $\begin{array}{c}0.928^{* * *} \\
(0.147)\end{array}$ & $\begin{array}{c}3.997 \\
(3.544)\end{array}$ & $\begin{array}{c}1,232.224^{* * *} \\
(416.506)\end{array}$ & $\begin{array}{c}246.607^{* * *} \\
(60.797)\end{array}$ & $\begin{array}{c}33.775 \\
(69.336)\end{array}$ & $\begin{array}{c}246.336^{* * * *} \\
(42.903)\end{array}$ \\
\hline Ano $=2000$ & $\begin{array}{c}0.106^{* * * *} \\
(0.004)\end{array}$ & $\begin{array}{l}-0.153 \\
(0.108)\end{array}$ & $\begin{array}{c}168.822^{* * *} \\
(12.090)\end{array}$ & $\begin{array}{c}-6.636^{* * *} \\
(1.633)\end{array}$ & $\begin{array}{c}6.476^{* * *} \\
(1.919)\end{array}$ & $\begin{array}{c}-2.330^{* *} \\
(1.129)\end{array}$ \\
\hline Ano $=2010$ & $\begin{array}{c}0.195^{* * *} * \\
(0.006)\end{array}$ & $\begin{array}{l}-0.188 \\
(0.166)\end{array}$ & $\begin{array}{c}384.294^{* * *} \\
(17.332)\end{array}$ & $\begin{array}{c}-11.685^{* * *} \\
(2.404)\end{array}$ & $\begin{array}{c}3.671 \\
(2.959)\end{array}$ & $\begin{array}{c}-6.161^{* * *} \\
(1.730)\end{array}$ \\
\hline Constante & $\begin{array}{c}0.769 * * * \\
(0.086)\end{array}$ & $\begin{array}{c}13.260^{* * * *} \\
(2.438)\end{array}$ & $\begin{array}{l}173.919 \\
(321.107)\end{array}$ & $\begin{array}{c}264.282^{* * * *} \\
(35.155)\end{array}$ & $\begin{array}{c}300.359^{* * * *} \\
(43.380)\end{array}$ & $\begin{array}{c}260.279^{* * *} \\
(30.500)\end{array}$ \\
\hline No Observações & 1,543 & 1,543 & 1,543 & 1,543 & 1,535 & 1,543 \\
\hline No Municípios & 587 & 587 & 587 & 587 & 587 & 587 \\
\hline
\end{tabular}

Notas: Neste modelo todas as covariadas são ponderadas pelo propensity score. Valores positivos em ATT mostram que os indicadores estão melhorando. As variáveis Elevação do Terreno, Disponibilidade de Água e Linhas de Transmissão são fixas ao longo do tempo, portanto o efeito desaparece na estimação do DID. Erros-padrão robustos em parênteses. ${ }^{* * *}$ significante a $1 \%, * *$ significante a $5 \%,{ }^{*}$ significante a $10 \%$. 
Tabela 4: Estimativas do efeito médio do tratamento sobre os tratados (ATT) - $2^{\circ}$ Estágio

\begin{tabular}{lccccc}
\hline \hline & Analf. 11-14 & Analf. 15+ & Mortal. Infantil & Pobreza & Gini \\
\hline \multirow{2}{*}{ ATT } & & & & & \\
& $0.839^{* *}$ & 0.080 & $-0.850^{*}$ & -0.015 & $0.010^{*}$ \\
& $(0.385)$ & $(0.181)$ & $(0.467)$ & $(0.482)$ & $(0.005)$ \\
Transf. Govern. & $-73.054^{* * *}$ & $-29.863^{* * *}$ & $-88.180^{* * *}$ & $-30.059^{* *}$ & 0.108 \\
& $(12.944)$ & $(6.612)$ & $(17.483)$ & $(12.745)$ & $(0.116)$ \\
Razão Dep. & $609.790^{* * *}$ & $301.928^{* * *}$ & $612.922^{* * *}$ & $431.074^{* * *}$ & $-1.312^{* * *}$ \\
& $(39.816)$ & $(19.885)$ & $(52.961)$ & $(36.473)$ & $(0.313)$ \\
PIB per Capita & -3.316 & -1.892 & $51.485^{*}$ & 18.828 & 0.234 \\
& $(15.269)$ & $(7.514)$ & $(28.964)$ & $(19.367)$ & $(0.201)$ \\
População & $1,955.044^{*}$ & 803.697 & $3,606.305^{* *}$ & $13,921.561^{* * *}$ & 8.608 \\
& $(1,095.627)$ & $(631.934)$ & $(1,465.040)$ & $(1,164.463)$ & $(9.825)$ \\
Área & -365.443 & -644.677 & -969.404 & $1,527.776$ & -7.142 \\
Pop. Urbana & $(651.767)$ & $(433.748)$ & $(1,283.694)$ & $(1,272.614)$ & $(8.418)$ \\
& -36.535 & $-44.954^{* * *}$ & -7.362 & $-95.301^{* * *}$ & -0.185 \\
Ano = 2000 & $(22.935)$ & $(15.946)$ & $(34.520)$ & $(27.345)$ & $(0.249)$ \\
& $1.556^{* * *}$ & $-2.255^{* * *}$ & -0.727 & $-2.493^{* * *}$ & $-0.023^{* * *}$ \\
Ano = 2010 & $(0.577)$ & $(0.305)$ & $(0.818)$ & $(0.763)$ & $(0.007)$ \\
& $7.890^{* * *}$ & $-2.431^{* * *}$ & $-2.897^{* *}$ & $-3.216^{* * *}$ & $-0.102^{* * *}$ \\
Constante & $(0.973)$ & $(0.535)$ & $(1.423)$ & $(1.175)$ & $(0.010)$ \\
& $-55.380^{* * *}$ & -3.089 & $-47.216^{*}$ & $-197.517^{* * *}$ & $0.611^{* * *}$ \\
& $(16.452)$ & $(9.584)$ & $(24.243)$ & $(19.431)$ & $(0.167)$ \\
\hline No Observações & 1,521 & 1,543 & & & 1,533 \\
\hline No Municípios & 583 & 587 & 587 & 586 & 587 \\
\hline \hline
\end{tabular}

Notas: Neste modelo todas as covariadas são ponderadas pelo propensity score. Valores negativos em ATT mostram que os indicadores estão melhorando. As variáveis Elevação do Terreno, Disponibilidade de Água e Linhas de Transmissão são fixas ao longo do tempo, portanto o efeito desaparece na estimação do DID. Erros-padrão robustos em parênteses. *** significante a 1\%, ** significante a $5 \%,{ }^{*}$ significante a $10 \%$. 
Como as covariadas estão sendo ponderadas pelo propensity score, as estimativas não podem ser interpretadas como efeitos marginais. Neste caso, o mais adequado é olhar para os sinais destas correlações. Como já foi dito, existem duas variáveis para as quais se espera uma direção mais clara dos efeitos: PIB per Capita e População Urbana. No caso da variável População Urbana, os resultados encontrados vão na direção esperada, mostrando que municípios mais urbanizados apresentam melhores indicadores. No caso da variável PIB per capita, a correlação com a variável Mortalidade Infantil apresenta um sinal oposto ao que seria esperado, mas esta só é significante a $10 \%$.

Uma possível preocupação na estimação deste modelo é que os erros apresentem algum tipo de correlação serial, seja entre municípios ou no tempo. Para superar este problema, o modelo foi estimado novamente, clusterizando os erros ao nível estado-ano. Os resultados desta estimação encontram-se na Tabela 5. Na coluna (1) são apresentados os mesmos resultados das Tabelas 3 e 4 como baseline enquanto na coluna (2) os resultados da nova estimação. Os resultados permanecem significativos para as variáveis IDH-M e Índice de Gini, mas perdem significância nas variáveis Analfabetismo 11-14 anos e Mortalidade Infantil, sugerindo que algum tipo de correlação serial pode estar envolvida.

\subsection{Efeitos Heterogêneos}

Nesta seção são avaliados os possíveis efeitos heterogêneos do tratamento. Parece razoável supor que nem todos os municípios serão afetados da mesma maneira. A primeira heterogeneidade explorada é no volume de recursos distribuídos aos municípios. Para avaliar estes efeitos, a equação 4.4 foi estimada novamente, restringindo a amostra aos municípios em que o volume de compensações per capita supere determinados thresholds. Seria de se esperar que municípios que recebem mais recursos possam financiar mais e melhores políticas, obtendo assim resultados mais sólidos. Os resultados da Tabela 6 sugerem que isto acontece de modo mais evidente na variável Mortalidade Infantil. As estimativas pontuais das variáveis Anos de Estudo, Analfabetismo 11-14 anos e Analfabetismo 15+ anos sugerem o mesmo, mas não são estatisticamente significantes. As variáveis Analfabetismo 11-14 
Tabela 5: Efeito médio do tratamento sobre os tratados (ATT) ajustado à correlação serial

\begin{tabular}{|c|c|c|}
\hline & (1) & (2) \\
\hline IDH-M & $\begin{array}{c}0.011^{* * *} \\
(0.003)\end{array}$ & $\begin{array}{c}0.011^{* * *} \\
(0.004)\end{array}$ \\
\hline Anos Estudo & $\begin{array}{l}-0.099 \\
(0.082)\end{array}$ & $\begin{array}{c}-0.099 \\
(0.106)\end{array}$ \\
\hline Renda per capita & $\begin{array}{c}5.703 \\
(9.927)\end{array}$ & $\begin{array}{c}5.703 \\
(12.214)\end{array}$ \\
\hline Água & $\begin{array}{c}1.631 \\
(1.183)\end{array}$ & $\begin{array}{c}1.631 \\
(2.209)\end{array}$ \\
\hline Lixo & $\begin{array}{c}0.576 \\
(1.196)\end{array}$ & $\begin{array}{c}0.576 \\
(2.004)\end{array}$ \\
\hline Eletricidade & $\begin{array}{c}0.482 \\
(0.718)\end{array}$ & $\begin{array}{c}0.482 \\
(1.239)\end{array}$ \\
\hline Analfabetismo 11-14 anos & $\begin{array}{c}0.839 * * \\
(0.385)\end{array}$ & $\begin{array}{c}0.839 \\
(0.528)\end{array}$ \\
\hline Analfabetismo $15+$ anos & $\begin{array}{c}0.080 \\
(0.181)\end{array}$ & $\begin{array}{c}0.080 \\
(0.274)\end{array}$ \\
\hline Mortalidade Infantil & $\begin{array}{c}-0.850^{*} \\
(0.467)\end{array}$ & $\begin{array}{c}-0.850 \\
(0.872)\end{array}$ \\
\hline Pobreza & $\begin{array}{l}-0.015 \\
(0.482)\end{array}$ & $\begin{array}{l}-0.015 \\
(0.722)\end{array}$ \\
\hline Gini & $\begin{array}{c}0.010 * * \\
(0.005)\end{array}$ & $\begin{array}{c}0.010 * * \\
(0.005)\end{array}$ \\
\hline No Observações & 1,521 & 1,521 \\
\hline $\mathrm{N}^{\mathrm{o}}$ Municípios & 583 & 583 \\
\hline $\mathrm{N}^{\mathrm{o}}$ Clusters & - & 61 \\
\hline
\end{tabular}

Na coluna 1 os erros-padrão robustos estão em parênteses. Na coluna 2 são os erros-padrão clusterizados por estado-ano. ${ }^{* * *}$ significante a $1 \%,{ }^{* *}$ significante a $5 \%,{ }^{*}$ significante a $10 \%$. 
anos e Analfabetismo 15+ anos apresentam significância estatística a $10 \%$ apenas quando a amostra é restrita aos municípios que recebem compensações superiores a $\mathrm{R} \$ 40$ per capita. Todos estes resultados precisam ser vistos com cautela, porque ao restringir a amostra há uma significativa perda no número de observações.

Tabela 6: Efeitos heterogêneos

\begin{tabular}{|c|c|c|c|c|c|c|}
\hline & \multicolumn{6}{|c|}{ Compensações ( $\mathrm{R} \$$ per capita) } \\
\hline & $\geq 5$ & $\geq 10$ & $\geq 20$ & $\geq 30$ & $\geq 40$ & $\geq 50$ \\
\hline IDH-M & $\begin{array}{c}0.008^{* *} \\
(0.003)\end{array}$ & $\begin{array}{l}0.006^{*} \\
(0.004)\end{array}$ & $\begin{array}{c}0.005 \\
(0.004)\end{array}$ & $\begin{array}{c}0.004 \\
(0.004)\end{array}$ & $\begin{array}{c}0.004 \\
(0.004)\end{array}$ & $\begin{array}{c}0.004 \\
(0.005)\end{array}$ \\
\hline Anos Estudo & $\begin{array}{l}-0.128 \\
(0.090)\end{array}$ & $\begin{array}{l}-0.120 \\
(0.089)\end{array}$ & $\begin{array}{l}-0.068 \\
(0.097)\end{array}$ & $\begin{array}{l}-0.061 \\
(0.119)\end{array}$ & $\begin{array}{l}-0.010 \\
(0.129)\end{array}$ & $\begin{array}{c}0.025 \\
(0.154)\end{array}$ \\
\hline Renda per capita & $\begin{array}{l}-10.860 \\
(13.729)\end{array}$ & $\begin{array}{l}-15.813 \\
(14.146)\end{array}$ & $\begin{array}{c}-12.111 \\
(12.755)\end{array}$ & $\begin{array}{c}-16.777 \\
(12.928)\end{array}$ & $\begin{array}{c}-13.989 \\
(14.247)\end{array}$ & $\begin{array}{c}-15.663 \\
(16.545)\end{array}$ \\
\hline Água & $\begin{array}{c}1.407 \\
(2.245)\end{array}$ & $\begin{array}{c}0.806 \\
(2.118)\end{array}$ & $\begin{array}{c}1.859 \\
(2.112)\end{array}$ & $\begin{array}{c}2.874 \\
(2.203)\end{array}$ & $\begin{array}{l}2.430 \\
(2.422)\end{array}$ & $\begin{array}{c}2.433 \\
(2.846)\end{array}$ \\
\hline Lixo & $\begin{array}{c}3.215 \\
(2.127)\end{array}$ & $\begin{array}{c}3.313 \\
(2.075)\end{array}$ & $\begin{array}{c}3.213 \\
(2.128)\end{array}$ & $\begin{array}{l}3.787^{*} \\
(2.230)\end{array}$ & $\begin{array}{c}3.111 \\
(2.427)\end{array}$ & $\begin{array}{c}3.777 \\
(2.582)\end{array}$ \\
\hline Eletricidade & $\begin{array}{c}1.182 \\
(1.196)\end{array}$ & $\begin{array}{c}0.911 \\
(1.220)\end{array}$ & $\begin{array}{c}0.616 \\
(1.158)\end{array}$ & $\begin{array}{c}1.005 \\
(1.208)\end{array}$ & $\begin{array}{c}0.595 \\
(1.307)\end{array}$ & $\begin{array}{c}0.537 \\
(1.523)\end{array}$ \\
\hline Analf. 11-14 & $\begin{array}{l}-0.252 \\
(0.774)\end{array}$ & $\begin{array}{l}-0.648 \\
(0.815)\end{array}$ & $\begin{array}{l}-0.709 \\
(0.760)\end{array}$ & $\begin{array}{l}-1.050 \\
(0.821)\end{array}$ & $\begin{array}{l}-1.645^{*} \\
(0.852)\end{array}$ & $\begin{array}{c}-1.800^{*} \\
(0.930)\end{array}$ \\
\hline Analf. $15+$ & $\begin{array}{l}-0.407 \\
(0.353)\end{array}$ & $\begin{array}{c}-0.379 \\
(0.361)\end{array}$ & $\begin{array}{l}-0.464 \\
(0.328)\end{array}$ & $\begin{array}{l}-0.426 \\
(0.341)\end{array}$ & $\begin{array}{l}-0.617^{*} \\
(0.361)\end{array}$ & $\begin{array}{l}-0.683^{*} \\
(0.393)\end{array}$ \\
\hline Mortalidade Infantil & $\begin{array}{l}-1.470 \\
(0.936)\end{array}$ & $\begin{array}{l}-2.005^{*} \\
(1.073)\end{array}$ & $\begin{array}{c}-2.134^{*} \\
(1.153)\end{array}$ & $\begin{array}{c}-2.363^{*} \\
(1.263)\end{array}$ & $\begin{array}{c}-2.872^{* *} \\
(1.349)\end{array}$ & $\begin{array}{c}-2.643^{*} \\
(1.504)\end{array}$ \\
\hline Pobreza & $\begin{array}{c}0.272 \\
(0.648)\end{array}$ & $\begin{array}{c}0.495 \\
(0.706)\end{array}$ & $\begin{array}{c}0.807 \\
(0.695)\end{array}$ & $\begin{array}{c}0.324 \\
(0.723)\end{array}$ & $\begin{array}{c}0.125 \\
(0.728)\end{array}$ & $\begin{array}{c}0.783 \\
(0.789)\end{array}$ \\
\hline Gini & $\begin{array}{c}0.018^{* * *} \\
(0.006)\end{array}$ & $\begin{array}{c}0.021^{* * *} \\
(0.006)\end{array}$ & $\begin{array}{c}0.020^{* * *} \\
(0.007)\end{array}$ & $\begin{array}{c}0.018^{* * *} \\
(0.006)\end{array}$ & $\begin{array}{c}0.021^{* * *} * \\
(0.006)\end{array}$ & $\begin{array}{c}0.018^{* *} \\
(0.007)\end{array}$ \\
\hline $\begin{array}{l}\text { Efeitos Fixos } \\
\mathrm{N}^{\circ} \text { Observações } \\
\mathrm{N}^{\circ} \text { Municípios } \\
\mathrm{N}^{\circ} \text { Clusters }\end{array}$ & $\begin{array}{c}\text { Ano, Mun. } \\
1,127 \\
567 \\
131\end{array}$ & $\begin{array}{c}\text { Ano, Mun. } \\
1,010 \\
558 \\
130\end{array}$ & $\begin{array}{c}\text { Ano, Mun. } \\
922 \\
551 \\
120\end{array}$ & $\begin{array}{c}\text { Ano, Mun. } \\
853 \\
542 \\
115\end{array}$ & $\begin{array}{l}\text { Ano, Mun. } \\
806 \\
536 \\
108\end{array}$ & $\begin{array}{c}\text { Ano, Mun } \\
766 \\
531 \\
105\end{array}$ \\
\hline
\end{tabular}

Erros-padrão clusterizados por estado-ano em parênteses. ${ }^{* * *}$ significante a $1 \%$; ${ }^{* *}$ significante a $5 \%$; significante a $10 \%$.

A segunda forma de heterogeneidade diz respeito ao tempo de exposição ao tratamento. Para isto, restringiu-se a amostra de municípios tratados àqueles que começaram a receber compensações antes do ano 2000. Espera-se que estes municípios apresentem melhores indicadores, uma vez que pode levar algum tempo para que se possam criar 
políticas mais bem estruturadas. A Tabela 7 parece confirmar esta previsão. A primeira coluna inclui todos os municípios que receberam algum valor de compensação, desde que tenha sido antes de 2000. Estas estimativas são diretamente comparáveis às da coluna (2) da Tabela 5. As demais colunas são comparáveis à Tabela 6. Os resultados encontrados mostram que praticamente todos os indicadores são melhores quando os municípios recebem compensações há mais tempo e são ainda melhores quando estes municípios recebem mais recursos. 
Tabela 7: Efeitos heterogêneos: municípios tratados antes de 2000

\begin{tabular}{|c|c|c|c|c|c|c|c|}
\hline & \multicolumn{7}{|c|}{ Compensações ( $\mathrm{R} \$$ per capita) } \\
\hline & $\geq 0$ & $\geq 5$ & $\geq 10$ & $\geq 20$ & $\geq 30$ & $\geq 40$ & $\geq 50$ \\
\hline IDH-M & $\begin{array}{c}0.068^{* * * *} \\
(0.012)\end{array}$ & $\begin{array}{c}0.070^{* * * *} \\
(0.013)\end{array}$ & $\begin{array}{c}0.074^{* * * *} \\
(0.013)\end{array}$ & $\begin{array}{c}0.079^{* * *} \\
(0.014)\end{array}$ & $\begin{array}{c}0.082^{* * *} \\
(0.014)\end{array}$ & $\begin{array}{c}0.078^{* * *} \\
(0.014)\end{array}$ & $\begin{array}{c}0.080^{* * * *} \\
(0.013)\end{array}$ \\
\hline Anos de Estudo & $\begin{array}{l}-0.178 \\
(0.125)\end{array}$ & $\begin{array}{c}-0.287^{* *} \\
(0.132)\end{array}$ & $\begin{array}{l}-0.071 \\
(0.132)\end{array}$ & $\begin{array}{l}-0.013 \\
(0.134)\end{array}$ & $\begin{array}{l}-0.021 \\
(0.146)\end{array}$ & $\begin{array}{l}-0.082 \\
(0.163)\end{array}$ & $\begin{array}{l}-0.204 \\
(0.159)\end{array}$ \\
\hline Renda per capita & $\begin{array}{c}46.332 \\
(29.223)\end{array}$ & $\begin{array}{c}38.175 \\
(26.600)\end{array}$ & $\begin{array}{l}50.980^{*} \\
(29.321)\end{array}$ & $\begin{array}{c}75.619^{* *} \\
(30.006)\end{array}$ & $\begin{array}{c}81.502^{* *} \\
(33.814)\end{array}$ & $\begin{array}{c}96.918^{* * * *} \\
(33.659)\end{array}$ & $\begin{array}{c}106.455^{* * *} \\
(33.711)\end{array}$ \\
\hline Água & $\begin{array}{l}-1.554 \\
(3.289)\end{array}$ & $\begin{array}{l}-0.836 \\
(4.154)\end{array}$ & $\begin{array}{l}-0.390 \\
(4.039)\end{array}$ & $\begin{array}{l}2.847 \\
(3.699)\end{array}$ & $\begin{array}{c}2.938 \\
(3.891)\end{array}$ & $\begin{array}{c}1.407 \\
(4.097)\end{array}$ & $\begin{array}{l}-0.009 \\
(4.956)\end{array}$ \\
\hline Lixo & $\begin{array}{l}6.431^{*} \\
(3.822)\end{array}$ & $\begin{array}{c}9.279^{* *} \\
(4.618)\end{array}$ & $\begin{array}{c}11.576^{* *} \\
(4.907)\end{array}$ & $\begin{array}{c}11.508^{* *} \\
(5.123)\end{array}$ & $\begin{array}{c}10.728^{* *} \\
(5.072)\end{array}$ & $\begin{array}{l}7.813 \\
(5.059)\end{array}$ & $\begin{array}{l}8.456 \\
(5.149)\end{array}$ \\
\hline Eletricidade & $\begin{array}{l}-0.209 \\
(2.104)\end{array}$ & $\begin{array}{c}0.217 \\
(2.129)\end{array}$ & $\begin{array}{c}0.830 \\
(1.802)\end{array}$ & $\begin{array}{l}1.101 \\
(2.115)\end{array}$ & $\begin{array}{c}0.431 \\
(2.196)\end{array}$ & $\begin{array}{l}-0.787 \\
(2.135)\end{array}$ & $\begin{array}{l}-0.898 \\
(2.258)\end{array}$ \\
\hline Analfabetismo 11-14 anos & $\begin{array}{l}-0.523 \\
(1.328)\end{array}$ & $\begin{array}{l}-1.213 \\
(1.348)\end{array}$ & $\begin{array}{l}-0.822 \\
(1.439)\end{array}$ & $\begin{array}{l}-0.520 \\
(1.611)\end{array}$ & $\begin{array}{l}-0.149 \\
(1.798)\end{array}$ & $\begin{array}{l}-0.041 \\
(1.866)\end{array}$ & $\begin{array}{c}0.073 \\
(1.542)\end{array}$ \\
\hline Analfabetismo $15+$ anos & $\begin{array}{c}-2.180^{* * *} \\
(0.265)\end{array}$ & $\begin{array}{c}-2.620^{* * *} \\
(0.424)\end{array}$ & $\begin{array}{c}-2.456^{* * *} \\
(0.471)\end{array}$ & $\begin{array}{c}-2.812^{* * *} \\
(0.458)\end{array}$ & $\begin{array}{c}-2.859^{* * *} \\
(0.599)\end{array}$ & $\begin{array}{c}-2.899^{* * *} \\
(0.609)\end{array}$ & $\begin{array}{c}-3.191^{* * *} \\
(0.631)\end{array}$ \\
\hline Mortalidade Infantil & $\begin{array}{l}-0.282 \\
(1.027)\end{array}$ & $\begin{array}{l}-0.532 \\
(1.067)\end{array}$ & $\begin{array}{l}-1.201 \\
(1.228)\end{array}$ & $\begin{array}{l}-1.795 \\
(1.350)\end{array}$ & $\begin{array}{l}-2.248 \\
(1.464)\end{array}$ & $\begin{array}{l}-2.115 \\
(1.554)\end{array}$ & $\begin{array}{l}-2.036 \\
(1.656)\end{array}$ \\
\hline Pobreza & $\begin{array}{l}-1.615 \\
(1.339)\end{array}$ & $\begin{array}{c}-2.543^{* *} \\
(1.089)\end{array}$ & $\begin{array}{c}-3.233^{* * *} \\
(1.136)\end{array}$ & $\begin{array}{c}-3.502^{* * *} \\
(1.209)\end{array}$ & $\begin{array}{c}-4.313^{* * *} \\
(1.403)\end{array}$ & $\begin{array}{c}-4.078^{* * *} \\
(1.122)\end{array}$ & $\begin{array}{c}-3.065^{* * *} \\
(1.101)\end{array}$ \\
\hline Gini & $\begin{array}{l}0.023^{*} \\
(0.013)\end{array}$ & $\begin{array}{c}0.014 \\
(0.015)\end{array}$ & $\begin{array}{c}0.017 \\
(0.015)\end{array}$ & $\begin{array}{l}0.008 \\
(0.015)\end{array}$ & $\begin{array}{l}-0.002 \\
(0.016)\end{array}$ & $\begin{array}{l}-0.005 \\
(0.018)\end{array}$ & $\begin{array}{l}-0.000 \\
(0.017)\end{array}$ \\
\hline $\begin{array}{l}\text { Efeitos Fixos } \\
\mathrm{N}^{\circ} \text { Observações } \\
\mathrm{N}^{0} \text { Municípios } \\
\mathrm{N}^{\circ} \text { Clusters }\end{array}$ & $\begin{array}{c}\text { Ano, Mun. } \\
919 \\
346 \\
57\end{array}$ & $\begin{array}{c}\text { Ano, Mun. } \\
633 \\
332 \\
55\end{array}$ & $\begin{array}{c}\text { Ano, Mun. } \\
560 \\
323 \\
53\end{array}$ & $\begin{array}{c}\text { Ano, Mun. } \\
493 \\
318 \\
47\end{array}$ & $\begin{array}{c}\text { Ano, Mun. } \\
439 \\
308 \\
46\end{array}$ & $\begin{array}{c}\text { Ano, Mun. } \\
406 \\
302 \\
43\end{array}$ & $\begin{array}{c}\text { Ano, Mun, } \\
386 \\
299 \\
41\end{array}$ \\
\hline
\end{tabular}

Notas: Erros-padrão clusterizados por estado-ano em parênteses. ${ }^{* * *}$ significante a $1 \%$; ${ }^{* *}$ significante a $5 \%$; ${ }^{*}$ significante a $10 \%$. 


\section{Robustez dos Resultados}

Neste capítulo são apresentados alguns testes de robustez dos resultados encontrados. A principal ameaça à estratégia de identificação adotada é a existência de características não observáveis que podem estar correlacionadas tanto com o mecanismo de seleção para o tratamento quanto com as variáveis de resultado. A estimação de um modelo difference-in-differences resolve parte deste problema, porque compara a variação nas médias das variáveis de resultados dos municípios tratados com a variação nas médias dos municípios não tratados, controlando assim as características, observáveis ou não, que são constantes no tempo. Se os grupos de tratamento e controle forem suficientemente parecidos, a variação nas médias do grupo de controle é uma boa estimativa para o contrafactual, ou seja, o que teria acontecido com os municípios tratados se não tivessem recebido o tratamento. A hipótese de identificação mais importante neste framework é a de que municípios tratados e não tratados apresentariam o mesmo comportamento se não houvessem as compensações, mas esta hipótese não é testável. O que se pode fazer é checar se os dois grupos de municípios apresentavam uma tendência comum nas variáveis dependentes antes da existência do tratamento. Infelizmente, não foi possível obter dados anteriores a 1991 para algumas das variáveis dependentes. A Figura 4 mostra a evolução nos indicadores IDH-M, Mortalidade Infantil e Analfabetismo 15+ anos no período 1970 a 2010. 


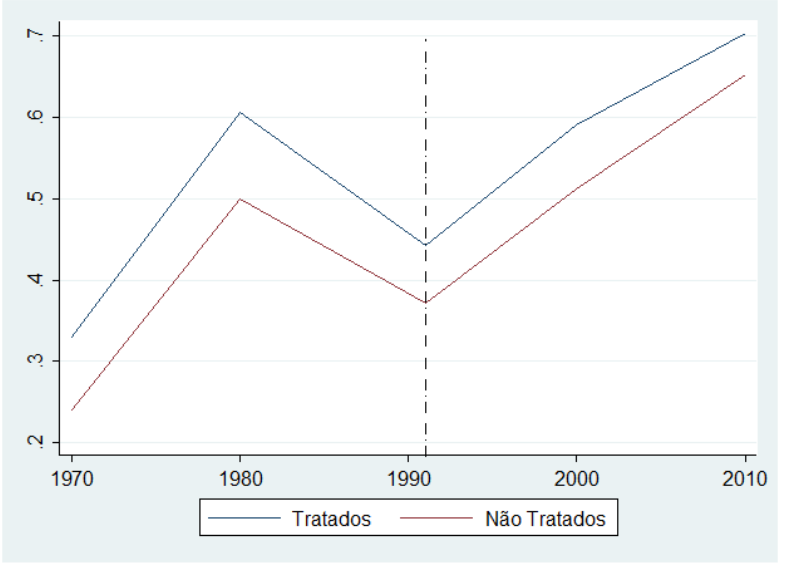

(a) IDH-M

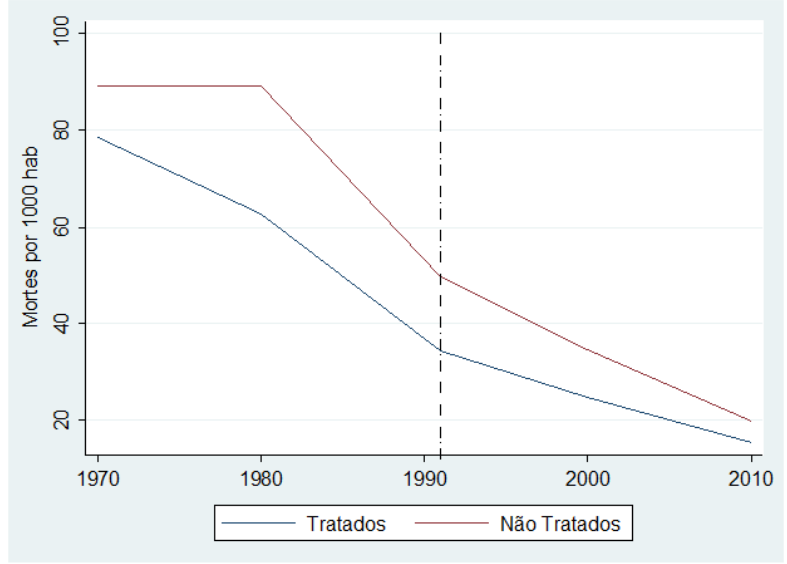

(b) Mortalidade Infantil

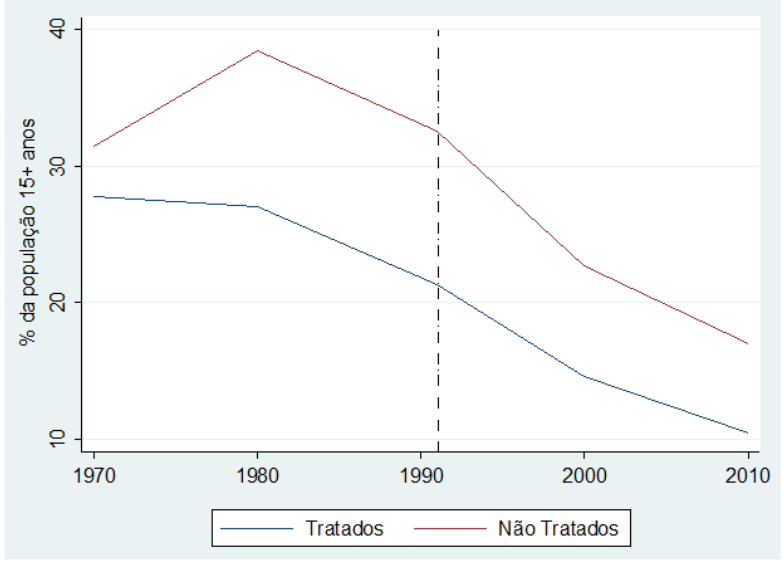

(c) Analfabetismo 15+ anos

Figura 4: Evolução dos indicadores socioeconômicos em municípios tratados e não tratados: 1970-2010 
Como pode ser visto, a tendência nos municípios tratados é similar à dos municípios não tratados na década anterior à implementação das compensações. Somado ao fato de que o balanceamento das covariadas parece ter sido bem sucedido, isto sugere que se há algum fator não observável variante no tempo que afeta tanto o tratamento quanto as variáveis de resultado, ele afeta ambos os grupos da mesma maneira e, portanto, não deveria estar confundindo a identificação.

Uma outra preocupação levantada é a de que alguma política realizada por outro nível de governo possa estar afetando as variáveis de resultado. Por exemplo, alguns municípios poderiam ter algum convênio com o governo estadual ou talvez pudessem estar usando recursos de fundos de desenvolvimento regional para financiar algum programa específico. Para tentar superar este problema, o modelo (4.4) foi estimado novamente incluindo tendências específicas para estado e região geográfica. A Tabela 8 mostra que a inclusão deste controle não altera muito os resultados encontrados. Apenas o coeficiente da variável Analfabetismo 11-14 anos aumenta um pouco e torna-se significante a 5\%, sugerindo que talvez haja alguma política implementada em outra esfera de governo que atenua o impacto negativo das compensações nesta dimensão.

Finalmente, considera-se a hipótese de que a própria implantação das usinas possa ter de alguma maneira afetado o desenvolvimento dos municípios onde elas foram instaladas. Isto significa que o efeito que estaria sendo capturado na estimação não é o verdadeiro efeito do tratamento (receber compensações), porque estaria sendo confundido com algum efeito de longo prazo induzido pela construção das usinas. Para lidar com este problema, foi feita uma nova estimação, tanto do primeiro quanto do segundo estágio, excluindo da amostra os municípios em que foram construídas as barragens e/ou casas de máquinas ${ }^{1}$. Assim, os municípios que sobram no grupo de tratamento são apenas aqueles que estão sendo afetados pela política via compensações. A Tabela 9 repete a tabela anterior aplicando esta restrição na amostra. Os resultados encontrados mostram que há pouca diferença entre os dois cenários, sugerindo que a implantação das usinas não gerou impactos muito

1 Para garantir a validade da hipótese de identificação, o balanceamento das covariadas foi testado nesta nova amostra, tanto na média quanto por decil. Novamente, os resultados reportados no apêndice sugerem que o balanceamento foi bem sucedido. 
Tabela 8: Efeito médio do tratamento sobre os tratados (ATT), incluindo tendências específicas de estado e região geográfica

\begin{tabular}{lccc}
\hline \hline & $(1)$ & $(2)$ & $(3)$ \\
\hline IDH-M & $0.011^{* * *}$ & $0.011^{* * *}$ & $0.010^{* * *}$ \\
& $(0.004)$ & $(0.003)$ & $(0.003)$ \\
Anos de Estudo & -0.099 & -0.096 & -0.118 \\
& $(0.106)$ & $(0.103)$ & $(0.092)$ \\
Renda per capita & 5.703 & 5.434 & 6.674 \\
& $(12.214)$ & $(11.187)$ & $(10.469)$ \\
Água & 1.631 & 1.698 & 1.288 \\
Lixo & $(2.209)$ & $(1.729)$ & $(1.499)$ \\
& 0.576 & 0.772 & 0.599 \\
Eletricidade & $(2.004)$ & $(1.713)$ & $(1.660)$ \\
& 0.482 & 0.546 & 0.378 \\
Analfabetismo 11-14 anos & $(1.239)$ & $(1.129)$ & $(1.070)$ \\
& & & \\
Analfabetismo 15+ anos & 0.839 & $0.837^{*}$ & $1.005 * *$ \\
Mortalidade Infantil & $(0.528)$ & $(0.464)$ & $(0.444)$ \\
& $(0.080$ & 0.063 & 0.135 \\
Pobreza & -0.850 & $(0.269)$ & $(0.241)$ \\
Gini & $(0.872)$ & $(0.724)$ & $(0.720)$ \\
& -0.015 & -0.060 & -0.083 \\
Efeitos Fixos & $(0.722)$ & $(0.582)$ & $(0.574)$ \\
Estado $\times$ Ano & $0.010^{* *}$ & $0.010^{* *}$ & $0.010^{* *}$ \\
Negião $\times$ Ano & $(0.005)$ & $(0.005)$ & $(0.005)$ \\
\hline \hline
\end{tabular}

Erros-padrão clusterizados por estado-ano em parênteses. ${ }^{* * *}$ significante a $1 \%$; ${ }^{* *}$ significante a $5 \%$; ${ }^{*}$ significante a $10 \%$. 
relevantes nos indicadores socioeconômicos dos municípios que as receberam.

Tabela 9: Efeito médio do tratamento sobre os tratados (ATT), incluindo tendências específicas de estado e região geográfica, excluindo municípios sede de barragens e/ou casa de máquinas

\begin{tabular}{|c|c|c|c|}
\hline & (1) & (2) & (3) \\
\hline IDH-M & $\begin{array}{c}0.009^{* * *} * \\
(0.003)\end{array}$ & $\begin{array}{c}0.009^{* * *} \\
(0.003)\end{array}$ & $\begin{array}{c}0.009^{* * *} \\
(0.003)\end{array}$ \\
\hline Anos de Estudo & $\begin{array}{l}-0.184 \\
(0.112)\end{array}$ & $\begin{array}{l}-0.180 \\
(0.108)\end{array}$ & $\begin{array}{c}-0.198^{* *} \\
(0.097)\end{array}$ \\
\hline Renda per capita & $\begin{array}{c}8.551 \\
(12.590)\end{array}$ & $\begin{array}{c}8.244 \\
(11.426)\end{array}$ & $\begin{array}{c}9.091 \\
(10.886)\end{array}$ \\
\hline Água & $\begin{array}{l}1.247 \\
(2.202)\end{array}$ & $\begin{array}{c}1.317 \\
(1.690)\end{array}$ & $\begin{array}{c}0.973 \\
(1.492)\end{array}$ \\
\hline Lixo & $\begin{array}{l}-0.096 \\
(2.102)\end{array}$ & $\begin{array}{c}0.051 \\
(1.822)\end{array}$ & $\begin{array}{c}-0.078 \\
(1.803)\end{array}$ \\
\hline Eletricidade & $\begin{array}{l}-0.179 \\
(1.227)\end{array}$ & $\begin{array}{l}-0.111 \\
(1.163)\end{array}$ & $\begin{array}{l}-0.248 \\
(1.114)\end{array}$ \\
\hline Analfabetismo 11-14 anos & $\begin{array}{c}0.799 \\
(0.554)\end{array}$ & $\begin{array}{l}0.804^{*} \\
(0.478)\end{array}$ & $\begin{array}{c}0.952^{* *} \\
(0.476)\end{array}$ \\
\hline Analfabetismo $15+$ anos & $\begin{array}{c}0.101 \\
(0.321)\end{array}$ & $\begin{array}{c}0.083 \\
(0.303)\end{array}$ & $\begin{array}{c}0.136 \\
(0.281)\end{array}$ \\
\hline Mortalidade Infantil & $\begin{array}{l}-0.577 \\
(0.923)\end{array}$ & $\begin{array}{l}-0.633 \\
(0.762)\end{array}$ & $\begin{array}{l}-0.555 \\
(0.768)\end{array}$ \\
\hline Pobreza & $\begin{array}{l}-0.072 \\
(0.801)\end{array}$ & $\begin{array}{l}-0.117 \\
(0.701)\end{array}$ & $\begin{array}{l}-0.118 \\
(0.696)\end{array}$ \\
\hline Gini & $\begin{array}{l}0.009^{*} \\
(0.005)\end{array}$ & $\begin{array}{l}0.009^{*} \\
(0.005)\end{array}$ & $\begin{array}{c}0.009 * \\
(0.005)\end{array}$ \\
\hline $\begin{array}{l}\text { Efeitos Fixos } \\
\text { Estado } \times \text { Ano } \\
\text { Região } \times \text { Ano }\end{array}$ & $\begin{array}{c}\text { Ano,Mun. } \\
\text { Não } \\
\text { Não }\end{array}$ & $\begin{array}{l}\text { Ano,Mun. } \\
\text { Sim } \\
\text { Não }\end{array}$ & $\begin{array}{l}\text { Ano,Mun. } \\
\text { Sim } \\
\text { Sim } \\
\end{array}$ \\
\hline $\begin{array}{l}\mathrm{N}^{\circ} \text { Observações } \\
\mathrm{N}^{0} \text { Municípios } \\
\mathrm{N}^{\circ} \text { Clusters }\end{array}$ & $\begin{array}{c}1,157 \\
441 \\
103\end{array}$ & $\begin{array}{c}1,157 \\
441 \\
103\end{array}$ & $\begin{array}{c}1,157 \\
441 \\
103\end{array}$ \\
\hline
\end{tabular}

Notas: A amostra utilizada exclui os municípios onde foram construídas barragens e/ou casas de máquinas. Erros-padrão clusterizados por estadoano em parênteses. $* * *$ significante a $1 \%$; ** significante a $5 \% ; *$ significante a $10 \%$. 



\section{Possíveis Canais dos Efeitos}

Neste capítulo é feita uma exploração introdutória dos possíveis canais pelos quais as compensações podem estar afetando os indicadores socioeconômicos analisados, à luz das teorias apresentadas no capítulo 2. É importante ressaltar que os resultados apresentados neste capítulo não podem ser considerados causais, representando apenas um exercício de apontar possíveis caminhos para trabalhos futuros.

Para as estimações apresentadas neste capítulo, foi construído um painel dos municípios brasileiros, com dados do período 2000-2012, utilizando as seguintes fontes:

- Compensações: Extraídas do sistema gerencial da ANEEL, disponíveis no website da agência. Inclui valores distribuídos aos municípios como CFURH e royalties de Itaipu.

- Campanhas de Vacinação: Extraídas do Departamento de Informática do Sistema Único de Saúde (DATASUS). Inclui número de doses de vacinas aplicadas e um indicador da cobertura de vacinação.

- Matrículas na rede municipal: Extraídas do Censo da Educação, disponível no website do Instituto Nacional de Estudos e Pesquisa Anísio Teixeira (INEP).

- Finanças públicas: Extraídas do FINBRA. Inclui receitas tributárias, transferências intra-governamentais, gastos com pessoal, investimentos, gastos nas rubricas Educação/Cultura e Saúde/Saneamento.

- Dados Eleitorais: Extraídos do website do Tribunal Superior Eleitoral (TSE).

- População residente e PIB Municipal: Extraídos do website do Instituto Brasileiro de Geografia e Estatística (IBGE).

O primeiro exercício realizado analisa o efeito das compensações sobre a provisão de bens públicos. Parte da literatura aponta que um aumento nas transferências inter- 
governamentais (compensações) deveria aumentar a provisão destes bens (LITSCHIG; MORRISON, 2013; ROBINSON; TORVIK; VERDIER, 2006) de modo que o prefeito em exercício pudesse obter apoio político para se reeleger. As Tabelas 10 e 11 mostram que no caso das compensações isto não parece acontecer. No caso do número de doses de vacinas distribuídas, a estimação por OLS mostra um efeito positivo e significante do volume de compensações per capita. Entretanto, ao controlar para as características políticas do município o efeito deixa de ser significante. Para a cobertura de vacinação, os efeitos são de pequena magnitude e não apresentam significância estatística. E nas matrículas na rede municipal, os efeitos também são de pequena magnitude e não significantes. 
Tabela 10: Impacto das compensações sobre a provisão de bens públicos: Vacinação, 2000-2012

\begin{tabular}{|c|c|c|c|c|c|c|}
\hline & \multicolumn{3}{|c|}{ Doses Vacina } & \multicolumn{3}{|c|}{ Cobertura Vacina } \\
\hline & (1) & $(2)$ & $(3)$ & (4) & $(5)$ & (6) \\
\hline Compensações per Capita & $\begin{array}{l}4.931^{* *} \\
(2.253)\end{array}$ & $\begin{array}{l}3.341 \\
(2.076)\end{array}$ & $\begin{array}{c}2.715 \\
(1.756)\end{array}$ & $\begin{array}{l}-0.007 \\
(0.006)\end{array}$ & $\begin{array}{l}-0.007 \\
(0.004)\end{array}$ & $\begin{array}{c}-0.008^{*} \\
(0.004)\end{array}$ \\
\hline PIB per Capita & $\begin{array}{c}34.418^{* *} \\
(16.350)\end{array}$ & $\begin{array}{c}8.447 \\
(14.718)\end{array}$ & $\begin{array}{c}3.901 \\
(14.479)\end{array}$ & $\begin{array}{c}0.070^{* * *} \\
(0.016)\end{array}$ & $\begin{array}{c}0.070^{* * *} \\
(0.015)\end{array}$ & $\begin{array}{c}0.075^{* * *} \\
(0.016)\end{array}$ \\
\hline Rec. Tributária per Capita & $\begin{array}{c}-15.518^{* * *} \\
(5.536)\end{array}$ & $\begin{array}{c}-9.870^{* *} \\
(4.164)\end{array}$ & $\begin{array}{c}-10.784^{* *} \\
(4.457)\end{array}$ & $\begin{array}{c}0.002^{* *} \\
(0.001)\end{array}$ & $\begin{array}{c}0.004^{* * *} \\
(0.001)\end{array}$ & $\begin{array}{c}0.004^{* * *} * \\
(0.001)\end{array}$ \\
\hline Transf. Gov. per Capita & $\begin{array}{c}0.147 \\
(1.085)\end{array}$ & $\begin{array}{c}3.329^{* * *} \\
(0.636)\end{array}$ & $\begin{array}{c}2.746^{* * *} \\
(0.638)\end{array}$ & $\begin{array}{c}0.000 \\
(0.000)\end{array}$ & $\begin{array}{l}-0.000 \\
(0.000)\end{array}$ & $\begin{array}{l}-0.000 \\
(0.000)\end{array}$ \\
\hline Desp. Pessoal per Capita & $\begin{array}{l}2.929^{*} \\
(1.637)\end{array}$ & $\begin{array}{l}-3.621^{*} \\
(1.885)\end{array}$ & $\begin{array}{c}-3.997^{* *} \\
(1.954)\end{array}$ & $\begin{array}{c}-0.001^{* *} \\
(0.001)\end{array}$ & $\begin{array}{l}-0.000 \\
(0.001)\end{array}$ & $\begin{array}{l}-0.000 \\
(0.001)\end{array}$ \\
\hline Investimentos per Capita & $\begin{array}{c}2.955 \\
(2.249)\end{array}$ & $\begin{array}{c}3.342 \\
(2.331)\end{array}$ & $\begin{array}{c}2.527 \\
(2.371)\end{array}$ & $\begin{array}{c}0.001 \\
(0.001)\end{array}$ & $\begin{array}{c}0.001 \\
(0.001)\end{array}$ & $\begin{array}{c}0.001 \\
(0.001)\end{array}$ \\
\hline Gastos Educação e Cultura per Capita & $\begin{array}{l}-2.493 \\
(1.537)\end{array}$ & $\begin{array}{c}0.085 \\
(2.100)\end{array}$ & $\begin{array}{c}3.131 \\
(2.480)\end{array}$ & $\begin{array}{l}-0.000 \\
(0.001)\end{array}$ & $\begin{array}{l}-0.001^{*} \\
(0.001)\end{array}$ & $\begin{array}{l}-0.002^{*} \\
(0.001)\end{array}$ \\
\hline Gastos Saúde e Saneam. per Capita & $\begin{array}{c}2.022 \\
(2.989)\end{array}$ & $\begin{array}{l}-0.257 \\
(2.650)\end{array}$ & $\begin{array}{l}-0.959 \\
(2.708)\end{array}$ & $\begin{array}{c}0.002^{* *} \\
(0.001)\end{array}$ & $\begin{array}{c}0.002^{* * *} * \\
(0.001)\end{array}$ & $\begin{array}{c}0.002^{* * *} \\
(0.001)\end{array}$ \\
\hline $\mathrm{N}^{\circ}$ Candidatos a Prefeito & & $\begin{array}{c}133.541 \\
(329.154)\end{array}$ & $\begin{array}{c}-9.562 \\
(331.801)\end{array}$ & & $\begin{array}{c}-2.002^{* * *} \\
(0.569)\end{array}$ & $\begin{array}{c}-1.422^{* *} \\
(0.602)\end{array}$ \\
\hline $\mathrm{N}^{\mathrm{o}}$ Candidatos a Vereador (por assento) & -125.145 & $\begin{array}{l}-103.395 \\
(102.171)\end{array}$ & $(101.528)$ & & $\begin{array}{c}0.121^{* *} \\
(0.051)\end{array}$ & $\begin{array}{l}0.119^{* *} \\
(0.051)\end{array}$ \\
\hline Partido Governador & & $\begin{array}{c}187.870 \\
(166.588)\end{array}$ & $\begin{array}{c}164.798 \\
(158.044)\end{array}$ & & $\begin{array}{l}-0.071 \\
(0.164)\end{array}$ & $\begin{array}{l}-0.048 \\
(0.160)\end{array}$ \\
\hline Partido Presidente & & $\begin{array}{c}-703.292^{* *} \\
(287.892)\end{array}$ & $\begin{array}{c}-756.107^{* * *} \\
(284.879)\end{array}$ & & $\begin{array}{c}0.057 \\
(0.254)\end{array}$ & $\begin{array}{c}0.015 \\
(0.254)\end{array}$ \\
\hline Prefeito em $2^{\circ}$ Mandato & & $\begin{array}{l}-274.384 \\
(417.675)\end{array}$ & $\begin{array}{c}-319.352 \\
(421.796)\end{array}$ & & $\begin{array}{l}-0.067 \\
(0.130)\end{array}$ & $\begin{array}{l}-0.043 \\
(0.128)\end{array}$ \\
\hline População (em log) & $\begin{array}{c}4,609.445^{* *} \\
(1,939.128)\end{array}$ & $\begin{array}{c}5,320.838^{* *} \\
(2,462.421)\end{array}$ & $\begin{array}{c}7,321.194^{* * *} \\
(2,595.466)\end{array}$ & $\begin{array}{c}-9.552^{* * *} \\
(1.094)\end{array}$ & $\begin{array}{c}-10.585^{* * * *} \\
(1.074)\end{array}$ & $\begin{array}{c}-10.294^{* * * *} \\
(1.073)\end{array}$ \\
\hline $\begin{array}{l}\text { Efeitos Fixos } \\
\text { Estado } \times \text { Ano }\end{array}$ & $\begin{array}{l}\text { Ano,Mun. } \\
\text { Não }\end{array}$ & $\begin{array}{c}\text { Ano,Mun. } \\
\text { Não }\end{array}$ & $\begin{array}{l}\text { Ano,Mun. } \\
\text { Sim }\end{array}$ & $\begin{array}{l}\text { Ano,Mun. } \\
\text { Não }\end{array}$ & $\begin{array}{l}\text { Ano,Mun. } \\
\text { Não }\end{array}$ & $\begin{array}{l}\text { Ano,Mun. } \\
\text { Sim }\end{array}$ \\
\hline $\begin{array}{l}\mathrm{N}^{\circ} \text { Observações } \\
\mathrm{N}^{\mathrm{o}} \text { Municípios }\end{array}$ & $\begin{array}{l}69,432 \\
5,561\end{array}$ & $\begin{array}{c}65,724 \\
5,548\end{array}$ & $\begin{array}{c}65,724 \\
5,548\end{array}$ & $\begin{array}{l}69,432 \\
5,561\end{array}$ & $\begin{array}{c}65,724 \\
5,548\end{array}$ & $\begin{array}{c}65,724 \\
5,548\end{array}$ \\
\hline
\end{tabular}

Notas: Doses Vacina é o número de doses aplicadas. Cobertura Vacina é dada pelo total de doses aplicadas dividido pela população alvo e multiplicado por 100. Partido Governador é uma dummy igual a 1 se o prefeito pertence ao mesmo partido do governador em exercício e 0 caso contrário. Partido Presidente é uma dummy igual a 1 se o prefeito pertence ao mesmo partido do presidente em exercício e 0 caso contrário. Prefeito em $2^{\circ}$ mandato é uma dummy igual a 1 se o prefeito está cumprindo o seu segundo mandato e 0 caso contrário. As colunas (1) e (4) apresentam a estimação por OLS. As colunas (2) e (5) incluem controles de características políticas. As colunas (3) e (6) incluem tendências específicas de estado. Erros-padrão robustos em parênteses. *** significante a $1 \%$. ** significante a $5 \%$. * 
Tabela 11: Impacto das compensações sobre a provisão de bens públicos: Matrículas na rede municipal, 2000-2012

\begin{tabular}{|c|c|c|c|c|c|c|c|c|c|}
\hline & \multicolumn{3}{|c|}{ Pré Escola } & \multicolumn{3}{|c|}{ Educação Fundamental } & \multicolumn{3}{|c|}{ Educação Jovens e Adultos } \\
\hline & (1) & $(2)$ & $(3)$ & $(4)$ & $(5)$ & (6) & $(7)$ & $(8)$ & (9) \\
\hline Compensações per Capita & $\begin{array}{l}-0.037 \\
(0.066)\end{array}$ & $\begin{array}{c}0.008 \\
(0.056)\end{array}$ & $\begin{array}{c}0.033 \\
(0.056)\end{array}$ & $\begin{array}{c}0.269 \\
(0.228)\end{array}$ & $\begin{array}{c}0.352 \\
(0.241)\end{array}$ & $\begin{array}{c}0.122 \\
(0.229)\end{array}$ & $\begin{array}{l}-0.080 \\
(0.051)\end{array}$ & $\begin{array}{l}-0.029 \\
(0.030)\end{array}$ & $\begin{array}{c}-0.001 \\
(0.026)\end{array}$ \\
\hline PIB per Capita & $\begin{array}{l}-0.374 \\
(0.540)\end{array}$ & $\begin{array}{l}-0.734 \\
(0.468)\end{array}$ & $\begin{array}{c}0.117 \\
(0.442)\end{array}$ & $\begin{array}{c}12.382^{* * *} \\
(3.145)\end{array}$ & $\begin{array}{c}11.095^{* * *} \\
(2.698)\end{array}$ & $\begin{array}{l}5.897^{* *} \\
(2.371)\end{array}$ & $\begin{array}{c}0.258 \\
(0.435)\end{array}$ & $\begin{array}{c}0.356 \\
(0.382)\end{array}$ & $\begin{array}{c}0.874^{* *} \\
(0.424)\end{array}$ \\
\hline Rec. Tributária per Capita & $\begin{array}{c}-0.424 \\
(0.266)\end{array}$ & $\begin{array}{c}-0.197^{* *} \\
(0.090)\end{array}$ & $\begin{array}{l}-0.120 \\
(0.090)\end{array}$ & $\begin{array}{c}0.522 \\
(0.635)\end{array}$ & $\begin{array}{c}1.231^{* * *} \\
(0.251)\end{array}$ & $\begin{array}{c}0.899^{* * *} \\
(0.231)\end{array}$ & $\begin{array}{l}-0.313 \\
(0.403)\end{array}$ & $\begin{array}{c}0.007 \\
(0.041)\end{array}$ & $\begin{array}{c}0.038 \\
(0.039)\end{array}$ \\
\hline Transf. Gov. per Capita & $\begin{array}{c}-0.063^{* *} \\
(0.025)\end{array}$ & $\begin{array}{l}-0.019 \\
(0.014)\end{array}$ & $\begin{array}{l}-0.013 \\
(0.014)\end{array}$ & $\begin{array}{l}-0.078 \\
(0.063)\end{array}$ & $\begin{array}{c}-0.152^{* *} \\
(0.076)\end{array}$ & $\begin{array}{c}-0.165^{* *} \\
(0.070)\end{array}$ & $\begin{array}{l}-0.047^{*} \\
(0.027)\end{array}$ & $\begin{array}{l}-0.024^{*} \\
(0.012)\end{array}$ & $\begin{array}{l}-0.021^{*} \\
(0.012)\end{array}$ \\
\hline Desp. Pessoal per Capita & $\begin{array}{l}0.162^{*} \\
(0.093)\end{array}$ & $\begin{array}{c}0.052^{* *} \\
(0.023)\end{array}$ & $\begin{array}{l}0.042^{*} \\
(0.023)\end{array}$ & $\begin{array}{l}-0.126 \\
(0.215)\end{array}$ & $\begin{array}{l}-0.051 \\
(0.113)\end{array}$ & $\begin{array}{l}-0.084 \\
(0.100)\end{array}$ & $\begin{array}{c}0.098 \\
(0.139)\end{array}$ & $\begin{array}{c}0.009 \\
(0.018)\end{array}$ & $\begin{array}{c}0.014 \\
(0.017)\end{array}$ \\
\hline Investimentos per Capita & $\begin{array}{l}0.044^{*} \\
(0.025)\end{array}$ & $\begin{array}{c}0.015 \\
(0.012)\end{array}$ & $\begin{array}{c}0.026^{* *} \\
(0.013)\end{array}$ & $\begin{array}{c}0.084 \\
(0.082)\end{array}$ & $\begin{array}{c}0.058 \\
(0.061)\end{array}$ & $\begin{array}{l}-0.033 \\
(0.061)\end{array}$ & $\begin{array}{c}0.007 \\
(0.035)\end{array}$ & $\begin{array}{l}-0.018^{*} \\
(0.010)\end{array}$ & $\begin{array}{c}0.005 \\
(0.010)\end{array}$ \\
\hline Gastos Educação e Cultura per Capita & $\begin{array}{c}0.065^{* * *} * \\
(0.023)\end{array}$ & $\begin{array}{c}0.071^{* * *} \\
(0.018)\end{array}$ & $\begin{array}{l}-0.006 \\
(0.020)\end{array}$ & $\begin{array}{c}0.108 \\
(0.101)\end{array}$ & $\begin{array}{l}-0.038 \\
(0.087)\end{array}$ & $\begin{array}{c}0.271^{* * *} * \\
(0.091)\end{array}$ & $\begin{array}{c}0.023 \\
(0.040)\end{array}$ & $\begin{array}{c}0.031^{* *} \\
(0.015)\end{array}$ & $\begin{array}{l}-0.023 \\
(0.015)\end{array}$ \\
\hline Gastos Saúde e Saneam. per Capita & $\begin{array}{c}-0.073^{* *} \\
(0.036)\end{array}$ & $\begin{array}{c}-0.086^{* * *} \\
(0.028)\end{array}$ & $\begin{array}{l}-0.007 \\
(0.029)\end{array}$ & $\begin{array}{l}0.323^{* *} \\
(0.151)\end{array}$ & $\begin{array}{c}0.270^{* *} \\
(0.125)\end{array}$ & $\begin{array}{c}0.047 \\
(0.130)\end{array}$ & $\begin{array}{c}0.069^{* *} \\
(0.034)\end{array}$ & $\begin{array}{c}0.034 \\
(0.021)\end{array}$ & $\begin{array}{c}0.079^{* * *} * \\
(0.023)\end{array}$ \\
\hline $\mathrm{N}^{\circ}$ Candidatos a Prefeito & & $\begin{array}{c}-45.198^{*} \\
(24.052)\end{array}$ & $\begin{array}{l}-35.472 \\
(24.695)\end{array}$ & & $\begin{array}{c}-110.171^{* *} \\
(48.509)\end{array}$ & $\begin{array}{c}-91.094^{* *} \\
(42.333)\end{array}$ & & $\begin{array}{l}-29.010 \\
(18.305)\end{array}$ & $\begin{array}{l}-22.511 \\
(17.144)\end{array}$ \\
\hline $\mathrm{N}^{\circ}$ Candidatos a Vereador (por assento) & & $\begin{array}{c}5.220 \\
(3.226)\end{array}$ & $\begin{array}{c}7.072^{* *} \\
(3.164)\end{array}$ & & $\begin{array}{c}12.574 \\
(10.609)\end{array}$ & $\begin{array}{c}12.865 \\
(10.100)\end{array}$ & & $\begin{array}{c}2.287 \\
(2.397)\end{array}$ & $\begin{array}{c}1.755 \\
(2.277)\end{array}$ \\
\hline Partido Governador & & $\begin{array}{c}-0.855 \\
(6.134)\end{array}$ & $\begin{array}{l}-0.372 \\
(5.674)\end{array}$ & & $\begin{array}{l}39.929^{*} \\
(23.167)\end{array}$ & $\begin{array}{c}5.148 \\
(22.623)\end{array}$ & & $\begin{array}{l}-2.453 \\
(5.014)\end{array}$ & $\begin{array}{c}0.496 \\
(4.956)\end{array}$ \\
\hline Partido Presidente & & $\begin{array}{c}4.894 \\
(12.838)\end{array}$ & $\begin{array}{c}-12.128 \\
(12.259)\end{array}$ & & $\begin{array}{c}-91.745^{* *} \\
(45.896)\end{array}$ & $\begin{array}{l}-54.321 \\
(44.314)\end{array}$ & & $\begin{array}{c}19.071^{* * *} \\
(9.370)\end{array}$ & $\begin{array}{c}2.361 \\
(9.016)\end{array}$ \\
\hline Prefeito em $2^{\circ}$ Mandato & & $\begin{array}{c}-14.442^{* * * *} \\
(4.900)\end{array}$ & $\begin{array}{l}-8.824^{*} \\
(4.657)\end{array}$ & & $\begin{array}{c}3.917 \\
(19.890)\end{array}$ & $\begin{array}{l}-17.109 \\
(19.592)\end{array}$ & & $\begin{array}{c}-12.039^{* * *} \\
(4.668)\end{array}$ & $\begin{array}{l}-8.548^{*} \\
(4.634)\end{array}$ \\
\hline População (em log) & $\begin{array}{c}342.036^{* * *} \\
(42.749)\end{array}$ & $\begin{array}{c}260.614^{* * *} \\
(27.729)\end{array}$ & $\begin{array}{c}193.472^{* * *} \\
(28.288)\end{array}$ & $\begin{array}{c}1,321.722^{* * *} \\
(243.178)\end{array}$ & $\begin{array}{c}1,247.287^{* * *} \\
(162.023)\end{array}$ & $\begin{array}{c}1,042.678^{* * *} \\
(148.792)\end{array}$ & $\begin{array}{c}146.578^{* * * *} \\
(52.630)\end{array}$ & $\begin{array}{c}79.599^{* * *} \\
(25.803)\end{array}$ & $\begin{array}{c}121.221^{* * *} \\
(24.761)\end{array}$ \\
\hline $\begin{array}{l}\text { Efeitos Fixos } \\
\text { Estado } \times \text { Ano } \\
\end{array}$ & $\begin{array}{l}\text { Ano,Mun. } \\
\text { Não }\end{array}$ & $\begin{array}{l}\text { Ano,Mun. } \\
\text { Não }\end{array}$ & $\begin{array}{l}\text { Ano,Mun. } \\
\text { Sim }\end{array}$ & $\begin{array}{l}\text { Ano,Mun. } \\
\text { Não }\end{array}$ & $\begin{array}{l}\text { Ano,Mun. } \\
\text { Não }\end{array}$ & $\begin{array}{l}\text { Ano,Mun. } \\
\text { Sim }\end{array}$ & $\begin{array}{l}\text { Ano,Mun. } \\
\text { Não }\end{array}$ & $\begin{array}{l}\text { Ano,Mun. } \\
\text { Não }\end{array}$ & $\begin{array}{l}\text { Ano,Mun. } \\
\text { Sim }\end{array}$ \\
\hline $\begin{array}{l}\mathrm{N}^{\circ} \text { Observações } \\
\mathrm{N}^{\mathrm{o}} \text { Municípios }\end{array}$ & $\begin{array}{c}69,117 \\
5,539\end{array}$ & $\begin{array}{l}65,426 \\
5,525\end{array}$ & $\begin{array}{l}65,426 \\
5,525\end{array}$ & $\begin{array}{c}69,120 \\
5,539\end{array}$ & $\begin{array}{c}65,429 \\
5,526\end{array}$ & $\begin{array}{c}65,429 \\
5,526\end{array}$ & $\begin{array}{c}69,122 \\
5,539\end{array}$ & $\begin{array}{c}65,430 \\
5,526\end{array}$ & $\begin{array}{c}65,430 \\
5,526\end{array}$ \\
\hline
\end{tabular}

Notas: Partido Governador é uma dummy igual a 1 se o prefeito pertence ao mesmo partido do governador em exercício e 0 caso contrário. Partido Presidente é uma dummy igual a 1 se o prefeito pertence ao mesmo partido do presidente em exercício e 0 caso contrário. Prefeito em $2^{\circ}$ mandato é uma dummy igual a 1 se o prefeito está cumprindo o seu segundo mandato e 0 caso contrário. As colunas (1), (4) e (7) apresentam a estimação por OLS. As colunas (2), (5) e (8) incluem controles de características políticas. As colunas (3), (6) e (9) incluem tendências específicas de estado. Erros-padrão robustos em parênteses. *** significante a $1 \%$. ** significante a $5 \%{ }^{*}$ significante a $10 \%$. 
Ao se considerar uma medida mais ampla de provisão de bens públicos (nível de gastos per capita nas rubricas Educação e Cultura; e Saúde e Saneamento), os resultados mostram que se há alguma relação, ela é o oposto do esperado. Os gastos com Educação e Cultura mostram uma relação negativa e estatisticamente significante com compensações per capita, enquanto com Saúde e Saneamento a relação é positiva (e de pequena magnitude), mas não significante. 
Tabela 12: Impacto das compensações sobre gastos públicos, 2000-2012

\begin{tabular}{|c|c|c|c|c|c|c|}
\hline & \multicolumn{3}{|c|}{ Educação e Cultura } & \multicolumn{3}{|c|}{ Saúde e Saneamento } \\
\hline & $(1)$ & $(2)$ & $(3)$ & $(4)$ & $(5)$ & $(6)$ \\
\hline Compensações per Capita & $\begin{array}{c}-0.321^{* * *} \\
(0.086)\end{array}$ & $\begin{array}{c}-0.210^{* * *} \\
(0.069)\end{array}$ & $\begin{array}{c}-0.153^{* * *} \\
(0.058)\end{array}$ & $\begin{array}{c}0.019 \\
(0.035)\end{array}$ & $\begin{array}{c}0.012 \\
(0.033)\end{array}$ & $\begin{array}{l}-0.002 \\
(0.029)\end{array}$ \\
\hline PIB per Capita & $\begin{array}{c}-4.620 * * * \\
(1.005)\end{array}$ & $\begin{array}{c}-3.510^{* * *} \\
(1.055)\end{array}$ & $\begin{array}{c}-2.459^{* * *} * \\
(0.882)\end{array}$ & $\begin{array}{c}0.284 \\
(0.502)\end{array}$ & $\begin{array}{c}0.148 \\
(0.461)\end{array}$ & $\begin{array}{c}-0.246 \\
(0.418)\end{array}$ \\
\hline Rec. Tributária per Capita & $\begin{array}{c}0.188^{* * *} \\
(0.060)\end{array}$ & $\begin{array}{c}0.258^{* * *} * \\
(0.055)\end{array}$ & $\begin{array}{c}0.287^{* * *} \\
(0.054)\end{array}$ & $\begin{array}{c}0.222^{* * *} \\
(0.052)\end{array}$ & $\begin{array}{c}0.146^{* * *} \\
(0.048)\end{array}$ & $\begin{array}{c}0.115^{* *} \\
(0.049)\end{array}$ \\
\hline Transf. Gov. per Capita & $\begin{array}{c}0.294^{* * *} * \\
(0.045)\end{array}$ & $\begin{array}{c}0.148^{* * *} * \\
(0.016)\end{array}$ & $\begin{array}{c}0.149 * * * \\
(0.015)\end{array}$ & $\begin{array}{c}0.097^{* * *} * \\
(0.016)\end{array}$ & $\begin{array}{c}0.137^{* * *} \\
(0.016)\end{array}$ & $\begin{array}{c}0.132^{* * *} \\
(0.015)\end{array}$ \\
\hline Desp. Pessoal per Capita & $\begin{array}{c}0.199^{* * *} * \\
(0.058)\end{array}$ & $\begin{array}{c}0.338^{* * *} * \\
(0.052)\end{array}$ & $\begin{array}{c}0.312^{* * *} \\
(0.050)\end{array}$ & $\begin{array}{c}0.252^{* * *} \\
(0.056)\end{array}$ & $\begin{array}{c}0.156^{* * *} \\
(0.045)\end{array}$ & $\begin{array}{c}0.151^{* * *} \\
(0.044)\end{array}$ \\
\hline Investimentos per Capita & $\begin{array}{c}0.094^{* * *} * \\
(0.020)\end{array}$ & $\begin{array}{c}0.084^{* * *} * \\
(0.018)\end{array}$ & $\begin{array}{c}0.090 * * * \\
(0.019)\end{array}$ & $\begin{array}{c}0.122^{* * *} \\
(0.024)\end{array}$ & $\begin{array}{c}0.109 * * * \\
(0.023)\end{array}$ & $\begin{array}{c}0.103^{* * *} * \\
(0.023)\end{array}$ \\
\hline Gastos Educação e Cultura per Capita & & & & $\begin{array}{c}-0.152^{* * * *} \\
(0.049)\end{array}$ & $\begin{array}{l}-0.059 \\
(0.040)\end{array}$ & $\begin{array}{l}-0.028 \\
(0.043)\end{array}$ \\
\hline Gastos Saúde e Saneam. per Capita & $\begin{array}{c}-0.261^{* *} \\
(0.101)\end{array}$ & $\begin{array}{l}-0.089 \\
(0.061)\end{array}$ & $\begin{array}{l}-0.039 \\
(0.060)\end{array}$ & & & \\
\hline No $^{\mathrm{O}}$ Candidatos a Prefeito & $\begin{array}{c}0.255 \\
(3.268)\end{array}$ & $\begin{array}{c}3.031 \\
(3.089)\end{array}$ & $\begin{array}{c}6.868^{* *} \\
(2.919)\end{array}$ & & $\begin{array}{c}1.514 \\
(2.093)\end{array}$ & $\begin{array}{c}-0.814 \\
(1.678)\end{array}$ \\
\hline No Candidatos a Vereador (por assento) & & $\begin{array}{c}2.823^{* * *} * \\
(0.641)\end{array}$ & $\begin{array}{l}1.069^{*} \\
(0.579)\end{array}$ & & $\begin{array}{c}0.507 \\
(0.430)\end{array}$ & $\begin{array}{c}0.514 \\
(0.401)\end{array}$ \\
\hline Partido Governador & & $\begin{array}{c}-3.138^{* *} \\
(1.489)\end{array}$ & $\begin{array}{c}0.377 \\
(1.319)\end{array}$ & & $\begin{array}{c}4.136^{* * *} \\
(1.097)\end{array}$ & $\begin{array}{c}2.270^{* *} \\
(0.995)\end{array}$ \\
\hline Partido Presidente & & $\begin{array}{l}1.408 \\
(2.314)\end{array}$ & $\begin{array}{c}5.237^{* *} \\
(2.109)\end{array}$ & & $\begin{array}{c}-2.404 \\
(1.664)\end{array}$ & $\begin{array}{l}-0.249 \\
(1.561)\end{array}$ \\
\hline Prefeito em $2^{\circ}$ Mandato & & $\begin{array}{l}2.768^{* *} \\
(1.220)\end{array}$ & $\begin{array}{c}3.648^{* * *} \\
(1.160)\end{array}$ & & $\begin{array}{c}0.701 \\
(0.900)\end{array}$ & $\begin{array}{l}-0.196 \\
(0.890)\end{array}$ \\
\hline População (em log) & $\begin{array}{c}108.429 * * * \\
(17.032)\end{array}$ & $\begin{array}{c}50.164^{* *} \\
(20.819)\end{array}$ & $\begin{array}{c}1.255 \\
(19.142)\end{array}$ & $\begin{array}{c}10.651 \\
(10.233)\end{array}$ & $\begin{array}{c}33.154^{* * *} \\
(10.643)\end{array}$ & $\begin{array}{c}31.830^{* * *} \\
(10.476)\end{array}$ \\
\hline $\begin{array}{l}\text { Efeitos Fixos } \\
\text { Estado x Ano }\end{array}$ & $\begin{array}{l}\text { Ano,Mun. } \\
\text { Não }\end{array}$ & $\begin{array}{l}\text { Ano,Mun. } \\
\text { Não }\end{array}$ & $\begin{array}{l}\text { Ano,Mun. } \\
\text { Sim }\end{array}$ & $\begin{array}{l}\text { Ano,Mun. } \\
\text { Não }\end{array}$ & $\begin{array}{l}\text { Ano,Mun. } \\
\text { Não }\end{array}$ & $\begin{array}{l}\text { Ano,Mun. } \\
\text { Sim }\end{array}$ \\
\hline $\mathrm{N}^{\mathrm{o}}$ Observações & 69,432 & 65,724 & 65,724 & 69,432 & 65,724 & 65,724 \\
\hline $\mathrm{N}^{\mathrm{o}}$ Municípios & 5,561 & 5,548 & 5,548 & 5,561 & 5,548 & 5,548 \\
\hline
\end{tabular}

Notas: Erros-padrão robustos em parênteses. *** significante a 1\%. ** significante a 5\%. ${ }^{*}$ significante a $10 \%$. 
Por outro lado, os gastos com pessoal apresentam uma correlação positiva com as compensações, o que é consistente com o modelo de Robinson, Torvik e Verdier (2006), apesar do fato de que a lei proíbe o uso destes recursos para este tipo de despesa. Uma possível explicação é que a Lei Complementar n 101/2000 (Lei de Responsabilidade Fiscal) estabelece um teto para a despesa total com pessoal de $60 \%$ da receita corrente líquida (RCL). Como as compensações são contabilizadas como um dos itens da RCL, os municípios beneficiários obtém um espaço para remanejar gastos de outras rubricas do orçamento para a conta de despesas com pessoal. A Tabela 13 mostra que mesmo controlando para as características políticas do município e incluindo tendências específicas de estado, o resultado é positivo e significante. É possível ainda que este canal ajude a explicar a piora identificada no Índice de Gini, se os rendimentos dos servidores públicos forem, em média, mais altos que os do restante da população.

Finalmente, a relação mais robusta parece ser com o nível de investimentos. A Tabela 14 mostra que as compensações apresentam uma correlação positiva e estatisticamente significante com o volume de investimentos per capita, mesmo quando são adicionados os controles para características políticas do município e tendências específicas de estado. Os resultados mostram que o nível de investimentos per capita tem uma correlação positiva com a disponibilidade de recursos (compensações, tributos e outras transferências) e com os gastos na provisão de bens públicos (educação e saúde). Como esta não é uma relação causal, pode ser que a interpretação seja oposta: maiores investimentos levam a um maior gasto de custeio. O resultado encontrado aqui parece ser consistente com a heterogeneidade explorada na Tabela 7. Se o principal canal dos efeito é via investimentos, faz sentido que municípios que recebem compensações há mais tempo apresentem melhores indicadores socioeconômicos, porque neste caso os investimentos já tiveram maior tempo de maturação. 
Tabela 13: Impacto das compensações sobre as despesas com pessoal, 2000-2012

\begin{tabular}{|c|c|c|c|}
\hline & (1) & $(2)$ & $(3)$ \\
\hline Compensações per Capita & $\begin{array}{c}0.318^{* * * *} \\
(0.075)\end{array}$ & $\begin{array}{c}0.146^{* * *} \\
(0.053)\end{array}$ & $\begin{array}{c}0.137^{* *} \\
(0.054)\end{array}$ \\
\hline PIB per Capita & $\begin{array}{c}-3.064^{* * *} \\
(1.129)\end{array}$ & $\begin{array}{c}-3.120^{* * * *} \\
(0.692)\end{array}$ & $\begin{array}{c}-3.104^{* * *} \\
(0.680)\end{array}$ \\
\hline Rec. Tributária per Capita & $\begin{array}{c}0.879^{* * *} * \\
(0.185)\end{array}$ & $\begin{array}{c}0.456^{* * *} \\
(0.100)\end{array}$ & $\begin{array}{c}0.457^{* * *} \\
(0.105)\end{array}$ \\
\hline Transf. Gov. per Capita & $\begin{array}{c}0.228^{* * *} * \\
(0.037)\end{array}$ & $\begin{array}{c}0.342^{* * *} \\
(0.031)\end{array}$ & $\begin{array}{c}0.339^{* * *} \\
(0.032)\end{array}$ \\
\hline Investimentos per Capita & $\begin{array}{c}-0.261^{* * *} \\
(0.054)\end{array}$ & $\begin{array}{c}-0.182^{* * *} \\
(0.030)\end{array}$ & $\begin{array}{c}-0.183^{* * *} \\
(0.031)\end{array}$ \\
\hline Gastos Educação e Cultura per Capita & $\begin{array}{c}0.235^{* * *} \\
(0.084)\end{array}$ & $\begin{array}{c}0.340^{* * *} \\
(0.045)\end{array}$ & $\begin{array}{c}0.348^{* * *} \\
(0.050)\end{array}$ \\
\hline Gastos Saúde e Saneam. per Capita & $\begin{array}{c}0.513^{* * *} \\
(0.138)\end{array}$ & $\begin{array}{c}0.238^{* * *} \\
(0.069)\end{array}$ & $\begin{array}{c}0.237^{* * *} \\
(0.068)\end{array}$ \\
\hline No Candidatos a Prefeito & & $\begin{array}{c}-7.300^{* * *} \\
(2.573)\end{array}$ & $\begin{array}{c}-5.951^{* *} \\
(2.477)\end{array}$ \\
\hline No Candidatos a Vereador (por assento) & & $\begin{array}{c}1.701^{* * *} \\
(0.644)\end{array}$ & $\begin{array}{c}1.920 * * * \\
(0.585)\end{array}$ \\
\hline Partido Governador & & $\begin{array}{l}-0.961 \\
(1.324)\end{array}$ & $\begin{array}{c}-0.827 \\
(1.291)\end{array}$ \\
\hline Partido Presidente & & $\begin{array}{c}3.186 \\
(1.971)\end{array}$ & $\begin{array}{c}2.461 \\
(1.958)\end{array}$ \\
\hline Prefeito em $2^{\circ}$ Mandato & & $\begin{array}{c}-4.300^{* * *} \\
(1.160)\end{array}$ & $\begin{array}{c}-3.961^{* * *} \\
(1.158)\end{array}$ \\
\hline População (em log) & $\begin{array}{c}-97.772^{* * *} \\
(24.606)\end{array}$ & $\begin{array}{c}-6.661 \\
(17.721)\end{array}$ & $\begin{array}{c}-6.107 \\
(16.674)\end{array}$ \\
\hline $\begin{array}{l}\text { Efeitos Fixos } \\
\text { Estado } \times \text { Ano }\end{array}$ & $\begin{array}{l}\text { Ano,Mun. } \\
\text { Não }\end{array}$ & $\begin{array}{c}\text { Ano,Mun. } \\
\text { Não }\end{array}$ & $\begin{array}{l}\text { Ano,Mun } \\
\text { Sim }\end{array}$ \\
\hline $\mathrm{N}^{\mathrm{o}}$ Observações & 69,432 & 65,724 & 65,724 \\
\hline $\mathrm{N}^{\mathrm{o}}$ Municípios & 5,561 & 5,548 & 5,548 \\
\hline
\end{tabular}

Notas: Erros-padrão robustos em parênteses. ${ }^{* * *}$ significante a $1 \%$. ${ }^{* *}$ significante a $5 \%$. * significante a $10 \%$. 
Tabela 14: Impacto das compensações sobre os investimentos, 2000-2012

\begin{tabular}{|c|c|c|c|}
\hline & (1) & $(2)$ & $(3)$ \\
\hline Compensações per Capita & $\begin{array}{c}0.371^{* * *} \\
(0.081)\end{array}$ & $\begin{array}{c}0.356^{* * *} \\
(0.081)\end{array}$ & $\begin{array}{c}0.342^{* * *} \\
(0.082)\end{array}$ \\
\hline PIB per Capita & $\begin{array}{l}1.385^{*} \\
(0.778)\end{array}$ & $\begin{array}{l}1.441^{*} \\
(0.772)\end{array}$ & $\begin{array}{c}1.110 \\
(0.795)\end{array}$ \\
\hline Rec. Tributária per Capita & $\begin{array}{c}0.251^{* * *} \\
(0.040)\end{array}$ & $\begin{array}{c}0.269^{* * *} \\
(0.041)\end{array}$ & $\begin{array}{c}0.254^{* * *} \\
(0.042)\end{array}$ \\
\hline Transf. Gov. per Capita & $\begin{array}{c}0.147^{* * *} \\
(0.015)\end{array}$ & $\begin{array}{c}0.142^{* * *} \\
(0.020)\end{array}$ & $\begin{array}{c}0.137^{* * *} \\
(0.021)\end{array}$ \\
\hline Desp. Pessoal per Capita & $\begin{array}{c}-0.302^{* * *} \\
(0.027)\end{array}$ & $\begin{array}{c}-0.300^{* * *} \\
(0.027)\end{array}$ & $\begin{array}{c}-0.299^{* * *} * \\
(0.029)\end{array}$ \\
\hline Gastos Educação e Cultura per Capita & $\begin{array}{c}0.129^{* * *} \\
(0.024)\end{array}$ & $\begin{array}{c}0.139^{* * *} \\
(0.023)\end{array}$ & $\begin{array}{c}0.164^{* * *} \\
(0.025)\end{array}$ \\
\hline Gastos Saúde e Saneam. per Capita & $\begin{array}{c}0.288^{* * *} \\
(0.041)\end{array}$ & $\begin{array}{c}0.275^{* * *} \\
(0.043)\end{array}$ & $\begin{array}{c}0.263^{* * *} \\
(0.045)\end{array}$ \\
\hline $\mathrm{N}^{\mathrm{o}}$ Candidatos a Prefeito & & $\begin{array}{l}-5.095 \\
(4.499)\end{array}$ & $\begin{array}{l}-3.971 \\
(4.239)\end{array}$ \\
\hline $\mathrm{N}^{\circ}$ Candidatos a Vereador (por assento) & & $\begin{array}{c}-1.487^{* * *} \\
(0.562)\end{array}$ & $\begin{array}{c}-0.997^{*} \\
(0.576)\end{array}$ \\
\hline Partido Governador & & $\begin{array}{l}-1.088 \\
(1.736)\end{array}$ & $\begin{array}{l}-0.801 \\
(1.632)\end{array}$ \\
\hline Partido Presidente & & $\begin{array}{c}5.391^{* *} \\
(2.153)\end{array}$ & $\begin{array}{c}1.350 \\
(2.083)\end{array}$ \\
\hline Prefeito em $2^{\circ}$ Mandato & & $\begin{array}{c}8.945^{* * *} \\
(1.326)\end{array}$ & $\begin{array}{c}7.639^{* * *} \\
(1.307)\end{array}$ \\
\hline População (em log) & $\begin{array}{c}-58.637^{* * *} \\
(16.712)\end{array}$ & $\begin{array}{c}-67.515^{* * *} \\
(18.820)\end{array}$ & $\begin{array}{c}-47.681^{* * *} \\
(17.694)\end{array}$ \\
\hline $\begin{array}{l}\text { Efeitos Fixos } \\
\text { Estado } \times \text { Ano }\end{array}$ & $\begin{array}{c}\text { Ano,Mun. } \\
\text { Não }\end{array}$ & $\begin{array}{l}\text { Ano,Mun. } \\
\text { Não }\end{array}$ & $\begin{array}{l}\text { Ano,Mun. } \\
\text { Sim }\end{array}$ \\
\hline No Observações & 69,432 & 65,724 & 65,724 \\
\hline $\mathrm{N}^{\circ}$ Municípios & 5,561 & 5,548 & 5,548 \\
\hline
\end{tabular}

Notas: Erros-padrão robustos em parênteses. *** significante a $1 \%$. ** significante a $5 \%$. * significante a $10 \%$. 



\section{Conclusão}

Os resultados encontrados neste trabalho sugerem que o impacto da CFURH e dos royalties de Itaipu sobre os indicadores socioeconômicos dos municípios beneficiários foi bastante limitado. Apesar de o IDH-M e a Mortalidade Infantil terem apresentado uma pequena melhora, a taxa de analfabetismo para a população de 11-14 anos e a concentração de renda (medida pelo Índice de Gini) pioraram. No entanto, estes efeitos não são os mesmos para todos os municípios tratados. Municípios que recebem maiores compensações, há mais tempo, apresentam um desempenho muito superior aos demais, em praticamente todas as dimensões avaliadas, sugerindo que o mecanismo de benefit sharing aqui é de mais longo prazo.

A estratégia empírica utilizada levou em conta a principal ameaça à identificação causal dos efeitos: a possibilidade de um viés de variável omitida. Os resultados encontrados parecem robustos a possíveis problemas na especificação.

A investigação sobre os possíveis canais pelos quais as compensações afetam os indicadores socioeconômicos mostra que o principal mecanismo parece ser via investimentos e via gastos com pessoal. Um aumento de $\mathrm{R} \$ 1,00$ per capita nas compensações está associado a um aumento de aproximadamente $\mathrm{R} \$ 0,34$ per capita nos investimentos e $\mathrm{R} \$ 0,14$ per capita nas despesas com o funcionalismo. Não foi encontrada nenhuma evidência de aumento na provisão de bens públicos. Uma discussão mais aprofundada destes canais, com maior atenção na identificação causal dos efeitos, pode ser objeto de futuros trabalhos.

Uma possível implicação em termos de política pública é colocar em debate os critérios de distribuição das compensações entre os entes federativos. É curioso que aos estados caiba o mesmo volume de recursos que é destinado aos municípios, dado que são estes os maiores afetados pelas usinas. 



\section{Referências}

ANEEL. A compensação financeira e seu município. [S.l.], 2014.

BANG, H.; ROBINS, J. M. Doubly robust estimation in missing data and causal inference models. Biometrics, 2005. Wiley Online Library, v. 61, n. 4, p. 962-973, 2005.

BECKMANN, M. J. A note on the optimal rates of resource exhaustion. The Review of Economic Studies, 1974. Oxford University Press, v. 41, n. 5, p. 121-122, 1974.

BIONDI, R. L. et al. Evaluating the impact of participation in the brazilian public school mathematical olympiad on math scores in students' standarized tests. JOURNAL OF LACEA ECONOMIA, 2012. LACEA-LATIN AMERICAN AND CARIBBEAN ECONOMIC ASSOCIATION, 2012.

BROLLO, F. et al. The political resource curse. The American Economic Review, 2013. v. 103, n. 5, p. 1759-1796, 2013.

BROOKHART, M. A. et al. Variable selection for propensity score models. American journal of epidemiology, 2006. Oxford Univ Press, v. 163, n. 12, p. 1149-1156, 2006.

CAMERON, A. C.; MILLER, D. L. A practitioner's guide to cluster-robust inference. Journal of Human Resources, 2015. University of Wisconsin Press, v. 50, n. 2, p. 317-372, 2015.

CARNICELLI, L.; POSTALI, F. A. S. Rendas do petróleo e tributos locais: uma análise de propensity score. Anais do XL Encontro Nacional de Economia-Anpec, 2012. 2012.

CASELLI, F.; MICHAELS, G. Do oil windfalls improve living standards? evidence from brazil. American Economic Journal: Applied Economics, 2013. v. 5, n. 1, p. 208-38, 2013. Disponível em: <http://www.aeaweb.org/articles.php?doi=10.1257/app.5.1.208>.

CERNEA, M. M. Compensation and benefit sharing: Why resettlement policies and practices must be reformed. Water Science and Engineering, 2008. Elsevier, v. 1, n. 1, p. 89-120, 2008.

DEHEJIA, R. H.; WAHBA, S. Propensity score-matching methods for nonexperimental causal studies. Review of Economics and statistics, 2002. MIT Press, v. 84, n. 1, p. 151-161, 2002.

GADENNE, L. Tax me, but spend wisely: sources of public finance and government accountability. Working Paper, University College London, 2013. 2013.

GALIANI, S.; GERTLER, P.; SCHARGRODSKY, E. Water for life: The impact of the privatization of water services on child mortality. Journal of political economy, 2005. JSTOR, v. 113, n. 1, p. 83-120, 2005.

GUO, S.; FRASER, M. W. Propensity score analysis: Statistical methods and applications. [S.l.]: Sage Publications, 2014.

IMBENS, G. W.; WOOLDRIDGE, J. M. Recent developments in the econometrics of program evaluation. In: CITESEER. Journal of Economic Literature. [S.l.], 2009. 
LECHNER, M. et al. The estimation of causal effects by difference-in-difference methods. [S.l.]: Now, 2011.

LIPSCOMB, M.; MOBARAK, M. A.; BARHAM, T. Development effects of electrification: Evidence from the topographic placement of hydropower plants in brazil. American Economic Journal: Applied Economics, 2013. American Economic Association, v. 5, n. 2, p. 200-231, 2013.

LITSCHIG, S.; MORRISON, K. M. The impact of intergovernmental transfers on education outcomes and poverty reduction. American Economic Journal: Applied Economics, 2013. American Economic Association, v. 5, n. 4, p. 206-240, 2013.

LUELLEN, J. K.; SHADISH, W. R.; CLARK, M. H. Propensity scores an introduction and experimental test. Evaluation Review, 2005. Sage Publications, v. 29, n. 6, p. 530-558, 2005.

MACDONALD, M. Report, Enhancing Development Benefits to Local Communities from Hydropower Projects. 2009.

MARTINEZ, L. R. Sources of revenue and local government performance: Evidence from colombia. Job Market Paper, London School of Economics and Political Science, 2015. 2015 .

MCDONALD, B. D. From compensation to development: Involuntary resettlement in the people's republic of china. 2006. 2006.

MEHLUM, H.; MOENE, K.; TORVIK, R. Institutions and the resource curse. The economic journal, 2006. Wiley Online Library, v. 116, n. 508, p. 1-20, 2006.

MOKOROSI, P. S.; ZAAG, P. van der. Can local people also gain from benefit sharing in water resources development? experiences from dam development in the orange-senqu river basin. Physics and Chemistry of the Earth, Parts $A / B / C, 2007$. Elsevier, v. 32, n. 15, p. 1322-1329, 2007.

MONASTERIO, L.; SOUSA, J. J. R. Transferências intergovernamentais no brasil: Um estudo sobre a compensação financeira pela utilização de recursos hídricos (2000-2010). 2014. 2014.

MORGAN, S. L.; WINSHIP, C. Counterfactuals and causal inference. [S.l.]: Cambridge University Press, 2014.

POSTALI, F. A. S. Petroleum royalties and regional development in brazil: The economic growth of recipient towns. Resources Policy, 2009. Elsevier, v. 34, n. 4, p. 205-213, 2009.

POSTALI, F. A. S.; NISHIJIMA, M. Distribuição das rendas do petróleo e indicadores de desenvolvimento municipal no brasil nos anos 2000s. Estudos Econômicos, 2011. v. 41, n. 2 , p. 463-485, 2011.

POSTALI, F. A. S.; NISHIJIMA, M. Oil windfalls in brazil and their long-run social impacts. Resources Policy, 2013. Elsevier, v. 38, n. 1, p. 94-101, 2013.

ROBINSON, J. A.; TORVIK, R.; VERDIER, T. Political foundations of the resource curse. Journal of Development Economics, 2006. Elsevier, v. 79, n. 2, p. 447-468, 2006. 
ROSENBAUM, P. R.; RUBIN, D. B. The central role of the propensity score in observational studies for causal effects. Biometrika, 1983. Biometrika Trust, v. 70, n. 1, p. 41-55, 1983.

ROTHMAN, M. P. Measuring and apportioning rents from hydroelectric power developments. [S.1.]: World Bank Publications, 2000.

SACHS, J. D.; WARNER, A. M. Natural resource abundance and economic growth. [S.l.], 1995.

TORVIK, R. Natural resources, rent seeking and welfare. Journal of development economics, 2002. Elsevier, v. 67, n. 2, p. 455-470, 2002.

WANG, C. A guide for local benefit sharing in hydropower projects. 2012. World Bank, Washington, DC, 2012.

WOOLDRIDGE, J. M. Econometric analysis of cross section and panel data. [S.1.]: MIT press, 2010. 

Apêndice 
Tabela 15: Estatísticas Descritivas: Variáveis dependentes

\begin{tabular}{|c|c|c|c|c|c|c|}
\hline \multirow[b]{3}{*}{ IDH-M } & \multicolumn{2}{|c|}{ 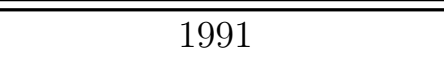 } & \multicolumn{2}{|c|}{2000} & \multicolumn{2}{|c|}{2010} \\
\hline & Tratados & Não Tratados & Tratados & Não Tratados & Tratados & Não Tratados \\
\hline & $\begin{array}{l}0.458 \\
(.075)\end{array}$ & $\begin{array}{l}0.395 \\
(.095)\end{array}$ & $\begin{array}{l}0.592 \\
(.078)\end{array}$ & $\begin{array}{l}0.517 \\
(.102)\end{array}$ & $\begin{array}{c}0.702 \\
(.0541)\end{array}$ & $\begin{array}{c}0.651 \\
(.0712)\end{array}$ \\
\hline Anos de Estudo & $\begin{array}{c}8.845 \\
(1.362)\end{array}$ & $\begin{array}{c}7.666 \\
(1.911)\end{array}$ & $\begin{array}{c}9.258 \\
(1.396)\end{array}$ & $\begin{array}{c}8.261 \\
(1.752)\end{array}$ & $\begin{array}{c}9.786 \\
(1.019)\end{array}$ & $\begin{array}{c}9.388 \\
(1.079)\end{array}$ \\
\hline Analfabetismo 11-14 Anos & $\begin{array}{c}8.435 \\
(10.197)\end{array}$ & $\begin{array}{c}20.863 \\
(18.732)\end{array}$ & $\begin{array}{c}3.213 \\
(4.339)\end{array}$ & $\begin{array}{c}7.883 \\
(8.263)\end{array}$ & $\begin{array}{c}2.008 \\
(1.998)\end{array}$ & $\begin{array}{l}4.006 \\
(3.879)\end{array}$ \\
\hline Analfabetismo $15+$ anos & $\begin{array}{l}20.408 \\
(9.431)\end{array}$ & $\begin{array}{c}31.291 \\
(16.609)\end{array}$ & $\begin{array}{l}14.623 \\
(7.202)\end{array}$ & $\begin{array}{c}22.600 \\
(12.614)\end{array}$ & $\begin{array}{c}10.612 \\
(5.762)\end{array}$ & $\begin{array}{c}17.241 \\
(10.019)\end{array}$ \\
\hline Mortalidade Infantil & $\begin{array}{c}33.246 \\
(13.127)\end{array}$ & $\begin{array}{c}48.655 \\
(23.316)\end{array}$ & $\begin{array}{l}24.764 \\
(8.312)\end{array}$ & $\begin{array}{c}34.220 \\
(14.002)\end{array}$ & $\begin{array}{l}15.480 \\
(4.256)\end{array}$ & $\begin{array}{l}19.942 \\
(7.283)\end{array}$ \\
\hline Renda per capita & $\begin{array}{c}337.467 \\
(142.235)\end{array}$ & $\begin{array}{c}240.066 \\
(141.205)\end{array}$ & $\begin{array}{c}454.055 \\
(177.665)\end{array}$ & $\begin{array}{c}325.846 \\
(186.989)\end{array}$ & $\begin{array}{c}624.528 \\
(206.477)\end{array}$ & $\begin{array}{c}466.399 \\
(235.481)\end{array}$ \\
\hline Pobreza Extrema & $\begin{array}{c}15.556 \\
(13.799)\end{array}$ & $\begin{array}{c}30.362 \\
(20.214)\end{array}$ & $\begin{array}{c}9.797 \\
(10.581)\end{array}$ & $\begin{array}{c}21.686 \\
(17.083)\end{array}$ & $\begin{array}{c}4.886 \\
(6.834)\end{array}$ & $\begin{array}{c}12.511 \\
(11.977)\end{array}$ \\
\hline Índice de Gini & $\begin{array}{l}0.536 \\
(.062)\end{array}$ & $\begin{array}{l}0.533 \\
(.065)\end{array}$ & $\begin{array}{l}0.541 \\
(.060)\end{array}$ & $\begin{array}{l}0.549 \\
(.068)\end{array}$ & $\begin{array}{l}0.481 \\
(.059)\end{array}$ & $\begin{array}{l}0.498 \\
(.065)\end{array}$ \\
\hline \% Pop. em domic. c/ água encanada & $\begin{array}{c}77.703 \\
(19.494)\end{array}$ & $\begin{array}{l}56.867 \\
(29.581)\end{array}$ & $\begin{array}{c}85.085 \\
(19.100)\end{array}$ & $\begin{array}{l}65.511 \\
(28.588)\end{array}$ & $\begin{array}{l}92.323 \\
(8.795)\end{array}$ & $\begin{array}{c}84.442 \\
(15.196)\end{array}$ \\
\hline \% Pop. em domic. c/ coleta de lixo & $\begin{array}{c}75.276 \\
(22.820)\end{array}$ & $\begin{array}{c}60.692 \\
(28.092)\end{array}$ & $\begin{array}{c}91.304 \\
(14.125)\end{array}$ & $\begin{array}{l}80.265 \\
(22.649)\end{array}$ & $\begin{array}{l}97.790 \\
(4.814)\end{array}$ & $\begin{array}{c}93.534 \\
(11.205)\end{array}$ \\
\hline \% Pop. em domic. c/ eletricidade & $\begin{array}{c}87.721 \\
(14.697)\end{array}$ & $\begin{array}{c}73.649 \\
(22.284)\end{array}$ & $\begin{array}{c}93.956 \\
(10.882)\end{array}$ & $\begin{array}{c}86.317 \\
(16.752)\end{array}$ & $\begin{array}{l}98.624 \\
(3.832)\end{array}$ & $\begin{array}{l}96.952 \\
(6.238)\end{array}$ \\
\hline $\mathrm{N}^{\mathrm{o}}$ Municípios & 568 & 3,132 & 693 & 4,451 & 692 & 4,618 \\
\hline
\end{tabular}

Desvios-padrão em parênteses. 
Tabela 16: Estatisticas descritivas: Covariadas

\begin{tabular}{|c|c|c|c|c|c|c|}
\hline & \multicolumn{2}{|c|}{1991} & \multicolumn{2}{|r|}{2000} & \multicolumn{2}{|c|}{2010} \\
\hline & Tratados & Não Tratados & Tratados & Não Tratados & Tratados & Não Tratados \\
\hline Elevação do Terreno & $\begin{array}{l}4.184 \\
(.625)\end{array}$ & $\begin{array}{c}4.11 \\
(.748)\end{array}$ & $\begin{array}{l}4.182 \\
(.633)\end{array}$ & $\begin{array}{l}4.064 \\
(.768)\end{array}$ & $\begin{array}{l}4.181 \\
(.629)\end{array}$ & $\begin{array}{c}4.04 \\
(.781)\end{array}$ \\
\hline Disponibilidade de Água & $\begin{array}{c}9.230 \\
(1.760)\end{array}$ & $\begin{array}{c}7.476 \\
(1.602)\end{array}$ & $\begin{array}{c}9.311 \\
(1.756)\end{array}$ & $\begin{array}{c}7.542 \\
(1.672)\end{array}$ & $\begin{array}{c}9.291 \\
(1.755)\end{array}$ & $\begin{array}{c}7.579 \\
(1.693)\end{array}$ \\
\hline Acesso a Linhas de Transmissão & $\begin{array}{l}0.627 \\
(.484)\end{array}$ & $\begin{array}{l}0.426 \\
(.495)\end{array}$ & $\begin{array}{l}0.631 \\
(.483)\end{array}$ & $\begin{array}{l}0.405 \\
(.491)\end{array}$ & $\begin{array}{l}0.633 \\
(.482)\end{array}$ & $\begin{array}{l}0.403 \\
(.490)\end{array}$ \\
\hline Transferências Governamentais & $\begin{array}{c}74.828 \\
(14.182)\end{array}$ & $\begin{array}{c}75.885 \\
(15.299)\end{array}$ & $\begin{array}{c}80.239 \\
(12.140)\end{array}$ & $\begin{array}{c}85.587 \\
(11.323)\end{array}$ & $\begin{array}{c}87.785 \\
(13.418)\end{array}$ & $\begin{array}{c}92.408 \\
(12.639)\end{array}$ \\
\hline PIB per capita & $\begin{array}{c}6.185 \\
(9.221)\end{array}$ & $\begin{array}{c}4.388 \\
(11.102)\end{array}$ & $\begin{array}{c}5.967 \\
(6.187)\end{array}$ & $\begin{array}{c}3.826 \\
(4.317)\end{array}$ & $\begin{array}{c}8.016 \\
(6.403)\end{array}$ & $\begin{array}{c}5.295 \\
(6.148)\end{array}$ \\
\hline População & $\begin{array}{c}9.553 \\
(1.135)\end{array}$ & $\begin{array}{c}9.512 \\
(1.003)\end{array}$ & $\begin{array}{c}9.495 \\
(1.207)\end{array}$ & $\begin{array}{c}9.374 \\
(1.095)\end{array}$ & $\begin{array}{c}9.575 \\
(1.240)\end{array}$ & $\begin{array}{c}9.442 \\
(1.121)\end{array}$ \\
\hline Área & $\begin{array}{c}6.438 \\
(1.115)\end{array}$ & $\begin{array}{c}6.241 \\
(1.255)\end{array}$ & $\begin{array}{c}6.381 \\
(1.121)\end{array}$ & $\begin{array}{c}6.171 \\
(1.273)\end{array}$ & $\begin{array}{c}6.392 \\
(1.122)\end{array}$ & $\begin{array}{c}6.219 \\
(1.287)\end{array}$ \\
\hline Razão de Dependência & $\begin{array}{c}64.328 \\
(10.605)\end{array}$ & $\begin{array}{c}74.519 \\
(15.745)\end{array}$ & $\begin{array}{l}55.865 \\
(8.422)\end{array}$ & $\begin{array}{c}62.881 \\
(12.057)\end{array}$ & $\begin{array}{l}47.558 \\
(6.232)\end{array}$ & $\begin{array}{l}52.219 \\
(9.029)\end{array}$ \\
\hline População Urbana & $\begin{array}{c}66.216 \\
(20.755)\end{array}$ & $\begin{array}{c}55.783 \\
(21.994)\end{array}$ & $\begin{array}{c}69.416 \\
(21.559)\end{array}$ & $\begin{array}{c}58.129 \\
(23.041)\end{array}$ & $\begin{array}{c}73.995 \\
(19.961)\end{array}$ & $\begin{array}{c}62.525 \\
(21.860)\end{array}$ \\
\hline $\mathrm{N}^{\circ}$ Municípios & 568 & 3,132 & 693 & 4.451 & 692 & 4.618 \\
\hline
\end{tabular}

Desvios-padrão em parênteses. 
Tabela 17: Balanceamento das covariadas, por decil

\begin{tabular}{ccccccccc}
\hline \hline & Elev. & Disp. Água & Transf. Gov. & PIB per Cap. & População & Área & Razão Dep. & Pop. Urbana \\
\hline \multirow{2}{*}{$1^{\text {o Decil }}$} & $0.350^{* * *}$ & 0.030 & 0.819 & $-0.084^{* *}$ & -0.008 & $0.102^{*}$ & $0.332^{*}$ & -0.214 \\
& $(0.087)$ & $(0.061)$ & $(0.825)$ & $(0.035)$ & $(0.025)$ & $(0.054)$ & $(0.172)$ & $(0.680)$ \\
$2^{\circ}$ Decil & 0.015 & -0.008 & -0.106 & 0.009 & 0.007 & -0.004 & $-0.258^{* * *}$ & 0.103 \\
& $(0.009)$ & $(0.017)$ & $(0.211)$ & $(0.018)$ & $(0.011)$ & $(0.012)$ & $(0.086)$ & $(0.322)$ \\
$3^{\circ}$ Decil & -0.008 & -0.009 & -0.023 & 0.022 & 0.000 & -0.002 & -0.070 & 0.032 \\
& $(0.007)$ & $(0.016)$ & $(0.142)$ & $(0.017)$ & $(0.009)$ & $(0.008)$ & $(0.080)$ & $(0.285)$ \\
$4^{\text {o Decil }}$ & -0.007 & 0.001 & 0.005 & 0.009 & -0.005 & 0.001 & -0.044 & 0.061 \\
& $(0.006)$ & $(0.014)$ & $(0.110)$ & $(0.020)$ & $(0.008)$ & $(0.007)$ & $(0.078)$ & $(0.224)$ \\
$5^{\circ}$ Decil & -0.003 & $-0.059^{* * *}$ & 0.001 & 0.021 & $0.021 * *$ & -0.000 & 0.046 & 0.076 \\
& $(0.006)$ & $(0.015)$ & $(0.095)$ & $(0.021)$ & $(0.009)$ & $(0.007)$ & $(0.081)$ & $(0.226)$ \\
$6^{\circ}$ Decil & 0.006 & -0.005 & $0.198^{* *}$ & -0.003 & 0.003 & 0.003 & 0.121 & -0.051 \\
& $(0.004)$ & $(0.015)$ & $(0.089)$ & $(0.020)$ & $(0.007)$ & $(0.009)$ & $(0.094)$ & $(0.197)$ \\
$7^{\circ}$ Decil & $-0.013^{* * *}$ & -0.004 & 0.038 & -0.006 & 0.004 & $0.034^{* * *}$ & 0.071 & 0.289 \\
& $(0.005)$ & $(0.014)$ & $(0.091)$ & $(0.020)$ & $(0.008)$ & $(0.009)$ & $(0.160)$ & $(0.199)$ \\
$8^{\circ}$ Decil & $-0.010^{*}$ & 0.000 & -0.006 & 0.007 & -0.002 & -0.017 & -0.372 & 0.188 \\
& $(0.005)$ & $(0.016)$ & $(0.084)$ & $(0.027)$ & $(0.009)$ & $(0.013)$ & $(0.256)$ & $(0.185)$ \\
$9^{\circ}$ Decil & -0.003 & -0.000 & $-0.357^{* * *}$ & 0.015 & $0.028^{*}$ & -0.020 & $1.376^{* * *}$ & -0.096 \\
& $(0.007)$ & $(0.020)$ & $(0.120)$ & $(0.051)$ & $(0.015)$ & $(0.021)$ & $(0.484)$ & $(0.185)$ \\
10 ${ }^{\circ}$ Decil & -0.007 & $-0.418^{* * *}$ & -0.122 & 0.638 & 0.073 & $-0.144^{* *}$ & -0.857 & 0.071 \\
& $(0.022)$ & $(0.061)$ & $(0.391)$ & $(0.994)$ & $(0.061)$ & $(0.069)$ & $(1.284)$ & $(0.228)$ \\
\hline \hline
\end{tabular}

Notas: Todas as colunas apresentam as diferenças de médias entre os grupos de tratamento e controle, por decil da respectiva variável. ${ }^{* *}$ significante a $1 \%$. $* *$ significante a $5 \%{ }^{*}$ significante a $10 \%$. 
Tabela 18: Balanceamento das covariadas, excluindo municípios sede de barragens e/ou casa de máquinas

\begin{tabular}{|c|c|c|c|}
\hline & Sem Correção & Suporte Comum & $\begin{array}{c}\text { Suporte Comum } \\
\& \\
\text { Propensity Score }\end{array}$ \\
\hline Elevação Terreno & $\begin{array}{c}0.146^{* * *} \\
(0.018)\end{array}$ & $\begin{array}{c}0.023 \\
(0.023)\end{array}$ & $\begin{array}{c}0.038 \\
(0.024)\end{array}$ \\
\hline Disponibilidade de Água & $\begin{array}{c}1.727^{* * *} \\
(0.039)\end{array}$ & $\begin{array}{c}0.869^{* * *} \\
(0.053)\end{array}$ & $\begin{array}{c}0.001 \\
(0.049)\end{array}$ \\
\hline Acesso a Linhas Trasmissão & $\begin{array}{c}0.226^{* * *} \\
(0.011)\end{array}$ & $\begin{array}{c}0.126^{* * *} \\
(0.016)\end{array}$ & $\begin{array}{c}0.008 \\
(0.016)\end{array}$ \\
\hline Transferências Governamentais & $\begin{array}{c}-3.878^{* * *} \\
(0.349)\end{array}$ & $\begin{array}{c}-1.594^{* * *} \\
(0.449)\end{array}$ & $\begin{array}{c}0.045 \\
(0.471)\end{array}$ \\
\hline PIB per Capita & $\begin{array}{c}2.304^{* * *} \\
(0.172)\end{array}$ & $\begin{array}{c}0.759^{* * *} \\
(0.250)\end{array}$ & $\begin{array}{c}0.014 \\
(0.262)\end{array}$ \\
\hline População & $\begin{array}{c}0.131^{* * *} \\
(0.026)\end{array}$ & $\begin{array}{c}0.118^{* * *} \\
(0.036)\end{array}$ & $\begin{array}{c}0.039 \\
(0.038)\end{array}$ \\
\hline Área & $\begin{array}{c}0.175^{* * * *} \\
(0.030)\end{array}$ & $\begin{array}{c}0.033 \\
(0.040)\end{array}$ & $\begin{array}{c}0.009 \\
(0.042)\end{array}$ \\
\hline Razão de Dependência & $\begin{array}{c}-7.666^{* * *} \\
(0.371)\end{array}$ & $\begin{array}{c}-1.779 * * * \\
(0.397)\end{array}$ & $\begin{array}{c}0.171 \\
(0.414)\end{array}$ \\
\hline População Urbana & $\begin{array}{c}10.994^{* * *} \\
(0.544)\end{array}$ & $\begin{array}{c}5.127^{* * *} \\
(0.699)\end{array}$ & $\begin{array}{l}-0.316 \\
(0.717)\end{array}$ \\
\hline
\end{tabular}

Notas: A primeira coluna apresenta as diferenças de médias entre os grupos de tratamento e controle sem nenhuma correção. A segunda coluna apresenta as diferenças apenas das variáveis pertencentes ao suporte comum. A terceira coluna apresenta as diferenças das variáveis ponderadas pelo propensity score e pertencentes ao suporte comum. Erros-padrão em parênteses. ${ }^{* * *}$ significante a $1 \%,{ }^{* *}$ significante a $5 \%,{ }^{*}$ significante a $10 \%$. 
Tabela 19: Balanceamento das covariadas, por decil, excluindo municípios sede de barragens e/ou casa de máquinas

\begin{tabular}{|c|c|c|c|c|c|c|c|c|}
\hline & Elev. & Disp. Água & Transf. Gov. & PIB per Cap. & População & Área & Razão Dep. & Pop. Urbana \\
\hline $1^{\circ}$ Decil & $\begin{array}{c}0.430 * * * \\
(0.095)\end{array}$ & $\begin{array}{c}0.021 \\
(0.066)\end{array}$ & $\begin{array}{c}0.666 \\
(0.962)\end{array}$ & $\begin{array}{c}-0.114^{* * *} \\
(0.036)\end{array}$ & $\begin{array}{l}-0.001 \\
(0.026)\end{array}$ & $\begin{array}{c}0.084 \\
(0.058)\end{array}$ & $\begin{array}{c}0.290 \\
(0.187)\end{array}$ & $\begin{array}{l}-0.722 \\
(0.782)\end{array}$ \\
\hline $2^{\circ}$ Decil & $\begin{array}{c}0.014 \\
(0.010)\end{array}$ & $\begin{array}{c}0.002 \\
(0.018)\end{array}$ & $\begin{array}{l}-0.245 \\
(0.234)\end{array}$ & $\begin{array}{l}-0.008 \\
(0.019)\end{array}$ & $\begin{array}{c}0.009 \\
(0.011)\end{array}$ & $\begin{array}{c}0.005 \\
(0.013)\end{array}$ & $\begin{array}{l}-0.179^{*} \\
(0.094)\end{array}$ & $\begin{array}{c}-0.014 \\
(0.368)\end{array}$ \\
\hline $3^{\circ}$ Decil & $\begin{array}{l}-0.012 \\
(0.007)\end{array}$ & $\begin{array}{l}-0.019 \\
(0.017)\end{array}$ & $\begin{array}{l}-0.100 \\
(0.157)\end{array}$ & $\begin{array}{c}0.021 \\
(0.020)\end{array}$ & $\begin{array}{l}-0.002 \\
(0.009)\end{array}$ & $\begin{array}{c}0.007 \\
(0.009)\end{array}$ & $\begin{array}{l}-0.109 \\
(0.089)\end{array}$ & $\begin{array}{c}0.020 \\
(0.320)\end{array}$ \\
\hline $4^{\circ}$ Decil & $\begin{array}{l}-0.007 \\
(0.006)\end{array}$ & $\begin{array}{c}0.000 \\
(0.017)\end{array}$ & $\begin{array}{l}-0.030 \\
(0.124)\end{array}$ & $\begin{array}{c}0.001 \\
(0.022)\end{array}$ & $\begin{array}{l}-0.002 \\
(0.009)\end{array}$ & $\begin{array}{c}0.007 \\
(0.008)\end{array}$ & $\begin{array}{l}-0.064 \\
(0.086)\end{array}$ & $\begin{array}{c}0.105 \\
(0.254)\end{array}$ \\
\hline $5^{\circ}$ Decil & $\begin{array}{l}-0.006 \\
(0.006)\end{array}$ & $\begin{array}{c}-0.057^{* * *} \\
(0.016)\end{array}$ & $\begin{array}{c}0.047 \\
(0.103)\end{array}$ & $\begin{array}{c}0.008 \\
(0.024)\end{array}$ & $\begin{array}{c}0.016 \\
(0.011)\end{array}$ & $\begin{array}{c}-0.007 \\
(0.008)\end{array}$ & $\begin{array}{c}0.059 \\
(0.090)\end{array}$ & $\begin{array}{c}0.018 \\
(0.243)\end{array}$ \\
\hline $6^{\circ}$ Decil & $\begin{array}{c}0.001 \\
(0.005)\end{array}$ & $\begin{array}{l}-0.010 \\
(0.017)\end{array}$ & $\begin{array}{c}0.257^{* * * *} \\
(0.099)\end{array}$ & $\begin{array}{l}-0.001 \\
(0.022)\end{array}$ & $\begin{array}{l}-0.002 \\
(0.008)\end{array}$ & $\begin{array}{c}0.009 \\
(0.011)\end{array}$ & $\begin{array}{c}0.095 \\
(0.106)\end{array}$ & $\begin{array}{c}0.001 \\
(0.219)\end{array}$ \\
\hline $7^{\circ}$ Decil & $\begin{array}{l}-0.008 \\
(0.006)\end{array}$ & $\begin{array}{c}-0.001 \\
(0.016)\end{array}$ & $\begin{array}{c}0.049 \\
(0.100)\end{array}$ & $\begin{array}{l}-0.001 \\
(0.023)\end{array}$ & $\begin{array}{l}-0.005 \\
(0.009)\end{array}$ & $\begin{array}{c}0.024^{* *} \\
(0.010)\end{array}$ & $\begin{array}{l}0.258 \\
(0.180)\end{array}$ & $\begin{array}{c}0.305 \\
(0.224)\end{array}$ \\
\hline $8^{\circ}$ Decil & $\begin{array}{l}-0.004 \\
(0.006)\end{array}$ & $\begin{array}{c}0.002 \\
(0.018)\end{array}$ & $\begin{array}{c}-0.369^{* * *} \\
(0.132)\end{array}$ & $\begin{array}{c}0.004 \\
(0.030)\end{array}$ & $\begin{array}{c}0.007 \\
(0.011)\end{array}$ & $\begin{array}{l}-0.007 \\
(0.014)\end{array}$ & $\begin{array}{l}-0.478 \\
(0.294)\end{array}$ & $\begin{array}{c}0.328 \\
(0.201)\end{array}$ \\
\hline $9^{\circ}$ Decil & $\begin{array}{l}-0.004 \\
(0.009)\end{array}$ & $\begin{array}{c}0.001 \\
(0.022)\end{array}$ & $\begin{array}{c}0.040 \\
(0.096)\end{array}$ & $\begin{array}{c}0.014 \\
(0.057)\end{array}$ & $\begin{array}{c}0.025 \\
(0.016)\end{array}$ & $\begin{array}{l}-0.001 \\
(0.023)\end{array}$ & $\begin{array}{c}1.281^{* * *} \\
(0.577)\end{array}$ & $\begin{array}{l}-0.164 \\
(0.203)\end{array}$ \\
\hline $10^{\circ}$ Decil & $\begin{array}{c}0.026 \\
(0.028)\end{array}$ & $\begin{array}{c}-0.425^{* * *} \\
(0.068)\end{array}$ & $\begin{array}{l}-0.372 \\
(0.412)\end{array}$ & $\begin{array}{l}-0.990 \\
(1.583)\end{array}$ & $\begin{array}{c}0.085 \\
(0.069)\end{array}$ & $\begin{array}{c}-0.230 * * * \\
(0.082)\end{array}$ & $\begin{array}{l}-0.282 \\
(1.399)\end{array}$ & $\begin{array}{c}0.014 \\
(0.254)\end{array}$ \\
\hline
\end{tabular}

Notas: Todas as colunas apresentam as diferenças de médias entre os grupos de tratamento e controle, por decil da respectiva variável. $* * *$ significante a $1 \%$.** significante a $5 \%{ }^{*}$ significante a $10 \%$. 